\title{
REVIEW OF ENDF/B-VI FISSION-PRODUCT CROSS SECTIONS
}

\author{
R. Q. Wright and R. E. MacFarlane*
}

Date Published:

*Los Alamos National Laboratory

\author{
Prepared by the \\ Oak Ridge National Laboratory \\ Oak Ridge, Tennessee 37831-2008 \\ Managed by \\ LOCKHEED MARTIN ENERGY RESEARCH CORP. \\ for the \\ U.S. DEPARTMENT OF ENERGY \\ under contract DE-AC05-96OR22464
}




\section{Contents}

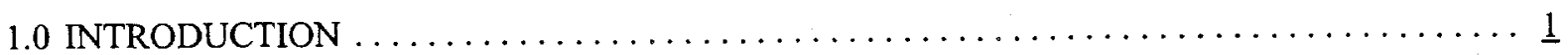

2.0 STATUS OF EXISTING EVALUATIONS FOR FISSION PRODUCT CROSS SECTIONS $\ldots \ldots \underline{2}$

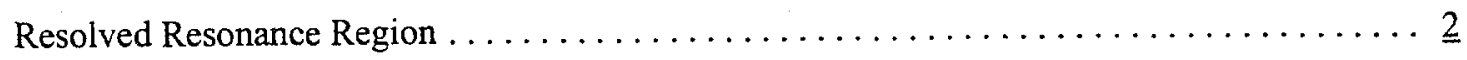

Unresolved Resonance Range . . . . . . . . . . . . . . . . . . . . . . . 3

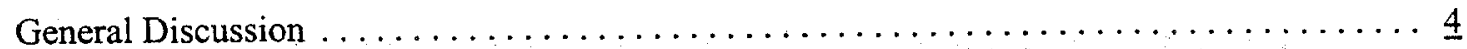

3.0 REVIEW OF ENDF/B-VI FISSION PRODUCT-PRODUCT CROSS SECTIONS FOR THE FAST

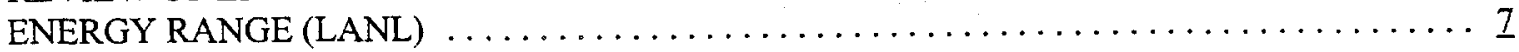

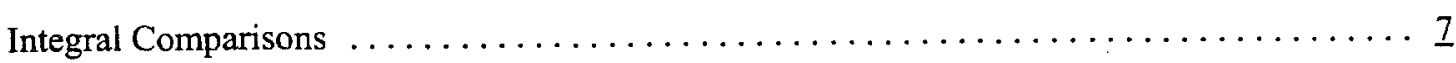

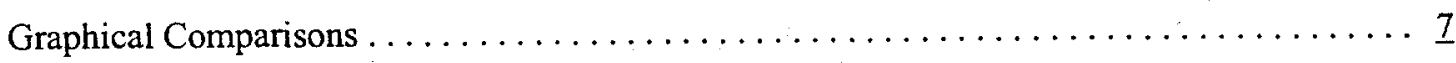

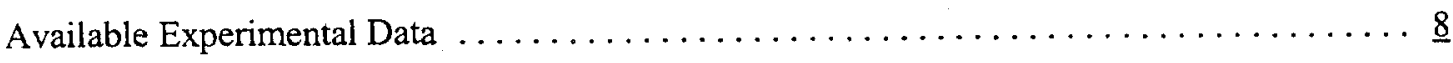

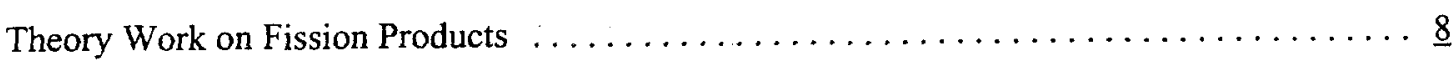

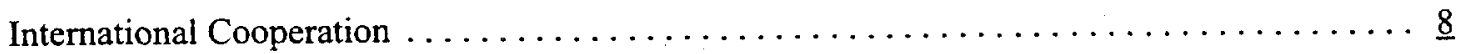

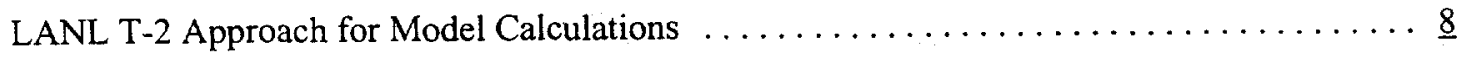

4.0 REVISED EVALUATIONS OF FISSION PRODUCT CROSS SECTIONS $\ldots \ldots \ldots \ldots \ldots q \underline{9}$

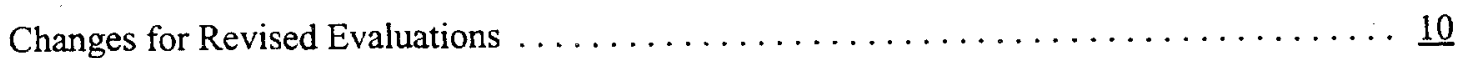

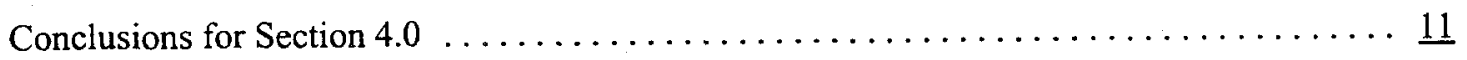

5.0 STATUS OF FISSION-PRODUCT CROSS SECTIONS FOR FASTREACTORS $\ldots \ldots \ldots \ldots \underline{12}$

Comparisons of One-Group Average Capture Cross Sections $\ldots \ldots \ldots \ldots \ldots \ldots \ldots \ldots \ldots \ldots$

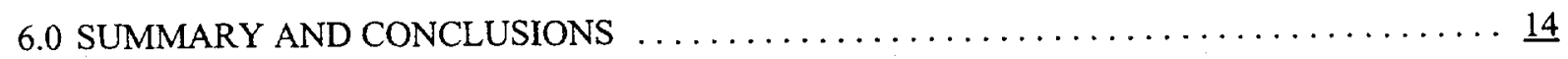

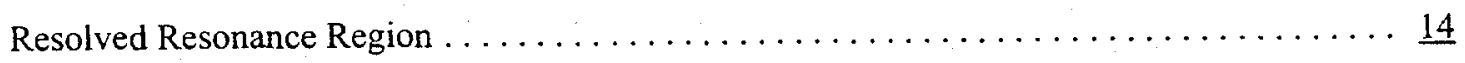

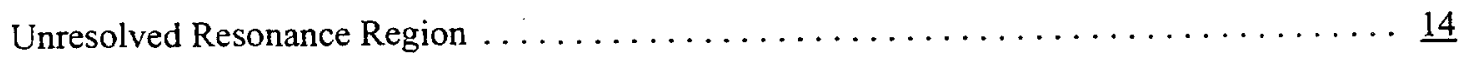

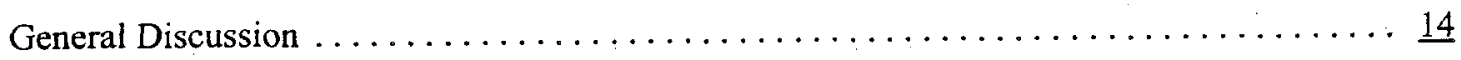

Status of Fission-Product Cross Sections for Fast Reactors $\ldots \ldots \ldots \ldots \ldots \ldots \ldots \ldots \ldots \ldots \ldots \ldots \ldots$

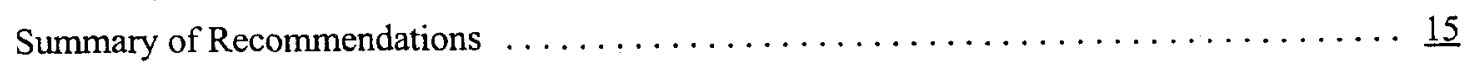

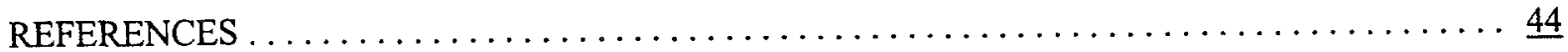

\section{List of Tables}

Table 1. Fission-product nuclides which do not have resonance parameters $\ldots \ldots \ldots \ldots \ldots \ldots$

Table 2. ENDF/B-VI Fission-Product Evaluations

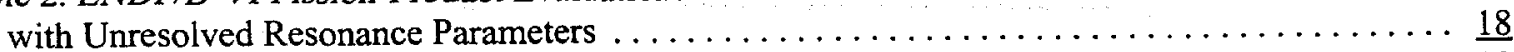

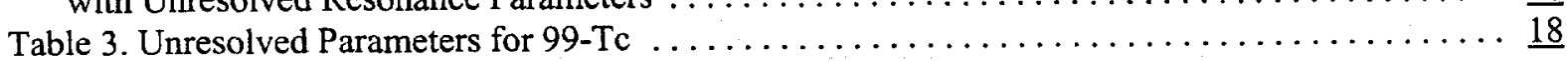




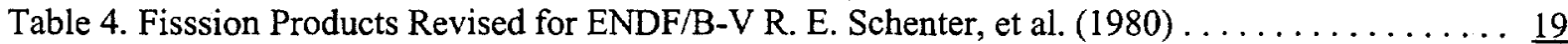

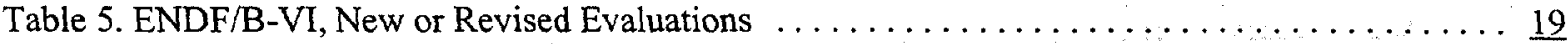

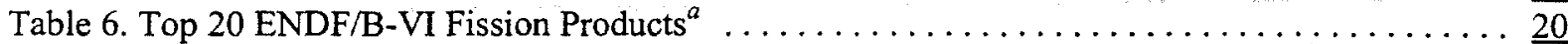

Table 7. Elements with Large Thermal Absorption Cross Sections $\ldots \ldots \ldots \ldots \ldots \ldots \ldots \ldots \ldots \ldots \ldots \ldots$

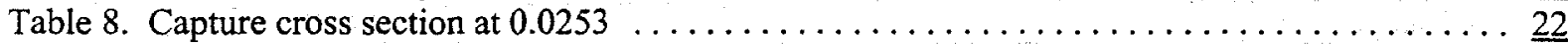

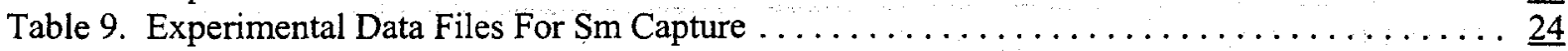

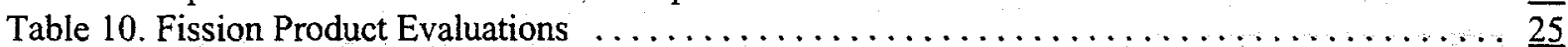

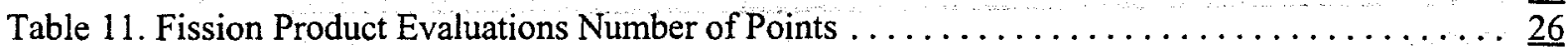

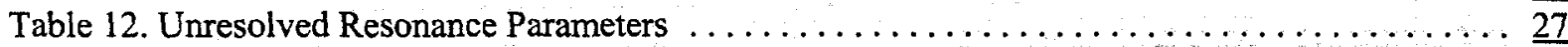

Table 13. Thermal Capture Cross Sections and Resonance Integrals $\ldots \ldots \ldots \ldots \ldots \ldots \ldots \ldots \ldots \frac{28}{28}$

Table 14. Maxwellian Averaged Capture Cross sections for $30 \mathrm{keV}(\mathrm{mb}) \ldots \ldots \ldots \ldots \ldots \ldots \ldots . \ldots \ldots$

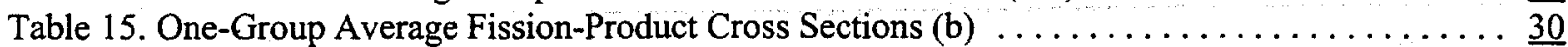

Table 16. One-Group Average Fission-Product Cross Sections (b) $\ldots \ldots \ldots \ldots \ldots \ldots \ldots \ldots \ldots \ldots \ldots \ldots$

Table 17. One-Group Average Fission-Product Capture Cross Sections (b) $\ldots \ldots \ldots \ldots \ldots \ldots$.

Table 18. One-Group Average Fission-Product Capture Cross Sections (b) $\ldots \ldots \ldots \ldots \ldots \ldots \ldots$

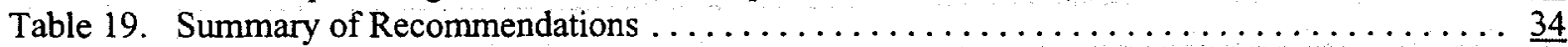

Table 20. Current Status and Recommendations for the Top 20 Fission-product Nuclides $\ldots \ldots \underline{35}$

\section{List of Figures}

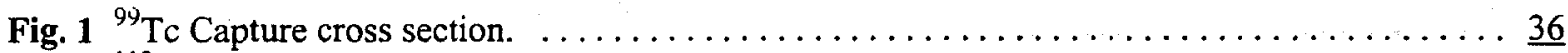

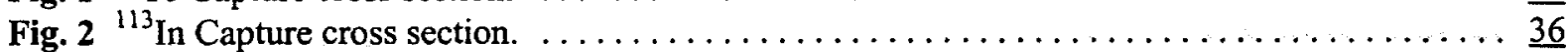

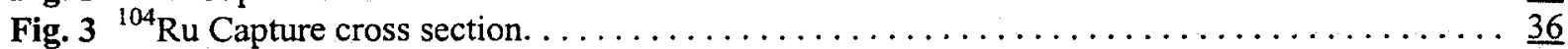

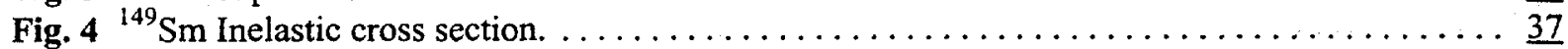

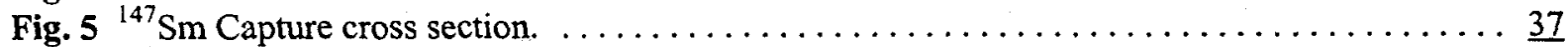

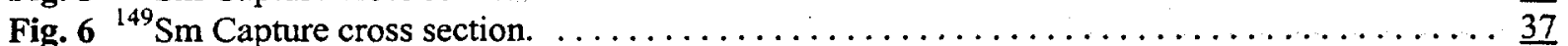

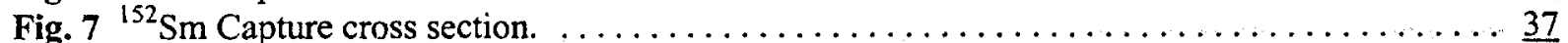

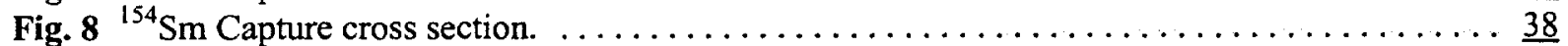

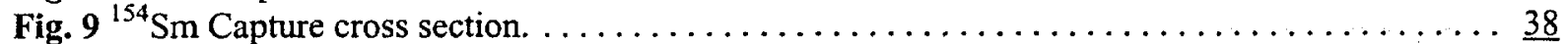

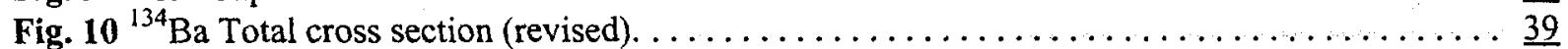

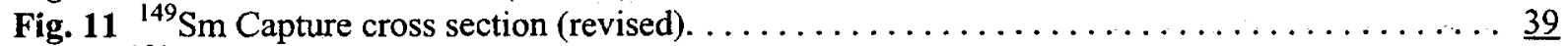

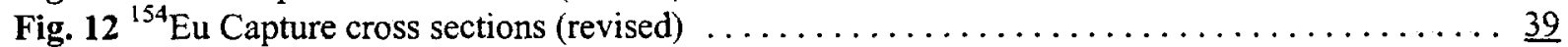

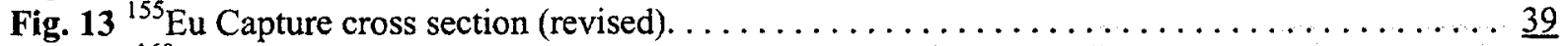

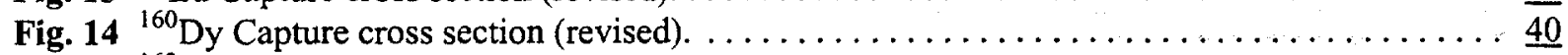

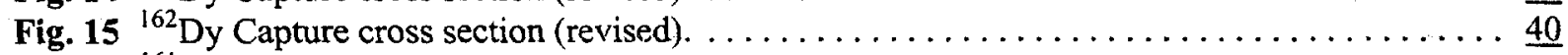

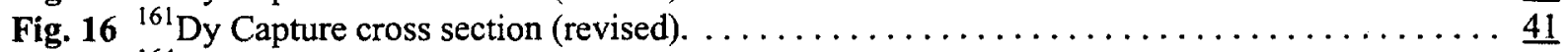

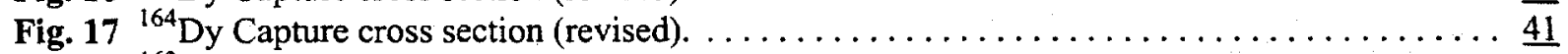

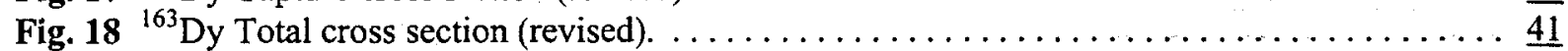

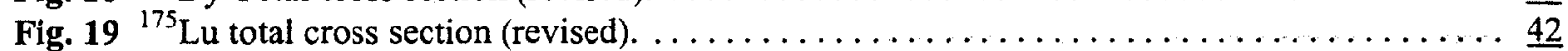

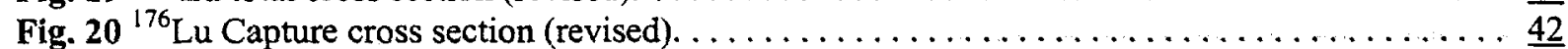

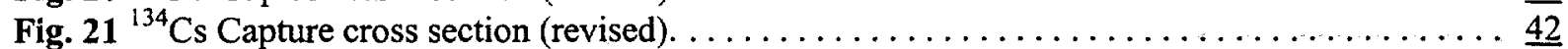

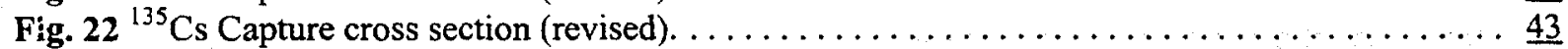

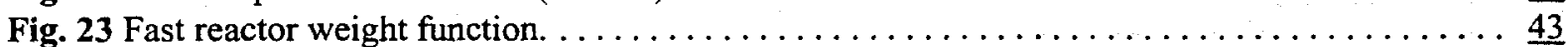




\subsection{INTRODUCTION}

In response to concerns raised in the Defense Nuclear Facilities Safety Board (DNFSB) Recommendation 93-2, the U.S. Department of Energy (DOE) developed a comprehensive program to help assure that the DOE maintain and enhance its capability to predict the criticality of systems throughout the complex. Tasks developed to implement the response to DNFSB recommendation 93-2 included Critical Experiments, Criticality Benchmarks, Training, Analytical Methods, and Nuclear Data. The Nuclear Data Task consists of a program of differential measurements at the Oak Ridge Electron Linear Accelerator (ORELA), precise fitting of the differential data with the generalized least-squares fitting code SAMMY to represent the data with resonance parameters using the Reich-Moore formalism along with covariance (uncertainty) information, and the development of complete evaluations for selected nuclides for inclusion in the Evaluated Nuclear Data File (ENDF/B).

The current ENDF/B library was developed for fast and thermal fission reactors and fusion reactors. Criticality safety practitioners recognize that many situations around the DOE complex are characterized by neutron spectra in the intermediate-energy region, as opposed to the high-energy region for fast reactors and fusion systems and the low-energy region for thermal reactors. Consequently, the Nuclear Data Task focuses primarily on the intermediate-energy region so that upgrades to existing evaluated data will remove deficiencies in the current ENDF/B evaluations. The ORELA allows high-resolution measurements in the intermediate-energy region and the SAMMY fitting code provides high quality resonance parameters in the resolved and unresolved energy range using the sophisticated Reich-Moore (RM) formalism for superior representation of the data in the intermediate energy region. In addition, the SAMMY fitting procedure provides covariance information for the resonance parameters that can be used in subsequent analyses to assess the uncertainty in calculated results and provide a better interpretation of criticality safety margins. Thus, the thrust of the Nuclear Data Task is to obtain highresolution data in the intermediate energy region and provide fits to the data that utilize the modern RM formalism and covariance information for subsequent use in criticality predictability applications.

As a subtask of the Nuclear Data Task, this review of the fission-product cross sections has several objectives. The first objective is a general data status review at various levels for the some 200 fission products. The second objective is a more detailed investigation of the top 20 fission products with regard to thermal- and intermediate-energy capture and scatter cross sections. The third objective is to demonstrate the revision of ENDF/B evaluations utilizing new data and evaluation techniques for 13 fission products. The fourth objective is to make recommendations for improvements, both specific and general in nature.

Section 2 of this report contains the data status review in terms of thermal cross sections, resolved resonance parameters and unresolved resonance data. The focus is on ENDFB data, particularly the ENDF/B-VI compilation. However, where appropriate, comparisons are made with the more-recent compilations made by the Japanese (JENDL), the Europeans (JEF) and the Russians (BROND). This section also contains a discussion of the importance of fission products to applications such as burnup credit, material disposition and the use of soluble and fixed absorbers.

Section 3 of this report focuses more on the intermediate range. Comparisons are given between experimental data and point data from various sources for capture and inelastic scattering. The information is given in both tabular and graphical format. Additional data resources from the CSISRS 
library of measured data are reviewed. The potential for greatly improving the inelastic scattering data with enhanced nuclear model codes at Los Alamos is discussed.

Section 4 of this report contains a detailed description of the revision of the ENDF/B-VI data for the 13 fission products. This includes increasing the number of resolved resonances, converting the resonance formulations from single-level Briet-Wigner to multilevel and Reich-Moore, and adding unresolved resonance data. Comparisons are made for thermal and intermediate spectral averaged values.

Section 5 of this report is primarily based on an international study of data averaged over a standard fast-reactor spectrum. Comparisons are made between the ENDF/B results and those developed from the foreign libraries. Emphasis is placed upon the top 20 fission products and the 13 revised ENDF/B-VI fission products.

Section 6 of this report contains summaries and conclusions organized along the lines of each of the previous sections. Table 19 contains a summary of the recommendations coming out of this review. The approach taken in this review is to include information of interest for general use including criticality safety, thermal reactors, fast reactors, control rods, etc. Some readers may only be concerned about the status of the most important fission products for use in calculations of criticality of LWR spent fuel. The top 20 fission products as determined by the absorption rate in spent fuel are shown in Table 6 . Readers concerned about the status and recommendations for these specific fission products can find this information in the sub-section "Summary of Recommendations" in Section 6.0 of this report. Table 20 discusses the status and recommendations for the "top 20 fission products" which are listed in Table 6.

\subsection{STATUS OF EXISTING EVALUATIONS FOR FISSION PRODUCT CROSS SECTIONS}

Fission products are potentially very important for criticality applications. However, none of the evaluations in the present ENDF/B library are up to the standards utilized in the Nuclear Data task for resolving deficiencies with regard to criticality safety applications. None of the present evaluations utilize the RM formalism for the resonance region and none have covariance data. This report summarizes the status of the currently available fission product cross sections and makes recommendations on how to improve the situation.

\section{Resolved Resonance Region}

There are about 200 nuclides in the current United States evaluated nuclear data file (ENDF/B-VI) for which cross sections are given in the fission-product range $(Z=31$ to 68$)$. Of these nuclides, 155 are charted as fission products from slow neutron fission of ${ }^{235} \mathrm{U}$. For several of the elements in the fissionproduct range, the lighter isotopes are not direct fission products. The indirect fission products result from beta decay chains fed by direct fission products of lower atomic numbers. The beta decay chains may terminate with stable isotopes or with neutron absorption by intermediate isotopes with long half lives. In these instances, the production of higher atomic number isotopes for a given mass number is terminated and these isotopes are said to be "shielded." Other nuclides may be produced by capture or $(n, 2 n)$ reactions. Of course there are quite a number of fission products, with short half-lives, for which cross sections are not currently available in ENDF/B-VI. In this review we will be concerned only with the fission products for which cross sections are available. 
For fission product evaluations the resolved resonance range is generally represented in one of three different ways:

1. SLBW - Single-level Breit-Wigner,

2. MLBW - Multilevel Breit-Wigner, or

3. Pointwise - no resonance parameters given.

Most of the newer evaluations use the MLBW formalism; the older evaluations used either the SLBW or pointwise representations. In the current ENDF/B-VI file the breakdown for the 155 direct fission-products is as follows:

FORMALISM

SLBW

MLBW

Pointwise
NUMBER OF

NUCLIDES

61

47

47

About $70 \%$ have either SLBW or MLBW parameters and about $30 \%$ use a pointwise representation. The MLBW formalism is generally considered the best representation and the pointwise method is considered the least desirable. When a pointwise representation is used, a detailed representation of the resonance structure is generally not included. In principle this can be done in a pointwise representation but may require a very large number of points. The use of resolved resonance parameters is a much more compact way to represent the data and is the preferred method.

Fission-product nuclides which do not have resonance parameters are shown in Table 1. Table 1 includes 47 direct fission products plus 8 others which are not direct fission products for a total of 55 nuclides. Most of the nuclides in Table 1 have short half-lives but there are 9 stable nuclides and 3 nuclides $\left({ }^{93} \mathrm{Zr},{ }^{126} \mathrm{Sn}\right.$, and $\left.{ }^{135} \mathrm{Cs}\right)$ with long half-lives. Seven of the nuclides in Table 1 are known to have resolved resonance parameters which have been determined experimentally. These are: ${ }^{93} \mathrm{Zr},{ }^{110} \mathrm{Pd}$, ${ }^{136} \mathrm{Xe},{ }^{135} \mathrm{Cs},{ }^{140} \mathrm{Ce},{ }^{142} \mathrm{Ce}$, and ${ }^{148} \mathrm{Sm}$.

\section{Unresolved Resonance Range}

In the previous section we discussed the resolved resonance range for fission-product nuclides. Resolved resonance parameters are given for a total of 108 nuclides. Many of the fission-product nuclides also have an unresolved resonance range, where the cross sections are described by the use of average resonance parameters. Unresolved resonance parameters are given for 30 fission-product nuclides. The ENDF/B-VI evaluations which include unresolved resonance parameters are given in Table 2. In comparing the ENDF/B-VI unresolved resonance region evaluations with corresponding evaluations in other files, i.e., JENDL-3.2, JEF-2.2, and BROND, we find considerable variation between the different evaluations. As an example we show the unresolved resonance parameters for ${ }^{99} \mathrm{Tc}$ in Table 3. There is a considerable variation between the various evaluations even for the basic parameters like the capture width, GW, and the s-wave level spacing, Do. We also see considerable variation for the pwave strength function, $\mathrm{S} 1$, and the scattering radius, $\mathrm{R}$. The BROND evaluation uses J-dependent capture widths, thus the values of GW are not directly comparable with the other files. The BEIJING file 
is a compilation of average neutron resonance parameters that was found on the internet; the reference is Huang Zhongfu et al., "New Sets of s-Wave Average Resonance Parameters," to be published.

One of the problems in the unresolved resonance range is that the same infinitely dilute cross section can be represented reasonably well with more than one set of unresolved resonance parameters. The elastic and total cross sections are dependent on the strength functions S0 and S1 and the scattering radius $R$. The capture cross section depends on the capture width, GW, and the s-wave level spacing, D0. Actually, to a considerable extent, the capture cross section depends on the ratio GW/D0. This implies that $\mathrm{GW}$ and $\mathrm{D} 0$ may have quite different values but the ratio, GW/D0, may still be nearly the same value.

The unresolved resonance parameters in the ENDF/B-VI and JENDL-3.2. ${ }^{99} \mathrm{Tc}$ evaluations result in the evaluated capture cross sections shown in Fig. 1. The ENDF/B-VI and JENDL-3.2. calculated capture cross sections are compared with the Macklin measured average capture cross section as given in $\mathrm{Nucl}$. Sci. Eng. 81: 520-24 (1982). The ENDF/B-VI evaluation also has non-zero values for the capture cross section in the $\mathrm{MF}=3$ smooth background, so that the final cross section is obtained by adding the MF = 3 and the unresolved resonance contributions. For the energy range 1 to $30 \mathrm{keV}$, the ENDF/B-VI MF $=3$ contribution is about 25 to $35 \%$ of the capture cross section. The use of a non-zero cross section in MF = 3 is very undesirable since it is only correct for the infinitely dilute case. The self-shielded cross sections will generally be incorrect when a non-zero $\mathrm{MF}=3$ contribution is given. The ENDF/B-VI ${ }^{99} \mathrm{Tc}$ unresolved resonance parameters need to be revised and the non-zero $\mathrm{MF}=3$ contribution eliminated.

\section{General Discussion}

ENDF/B-VI was initially released in 1990 , but the cross sections for the fission product evaluations ${ }^{1}$ generally date to the release of ENDF/B-IV in 1975. Evaluations for fission product capture cross sections for 36 important isotopes for fast reactors were upgraded for ENDF/B-V (1980) using a generalized least squares fitting procedure for differential and integral data. Fission products revised for ENDF/B-V by Schenter, et $\mathrm{al}^{2}$ are shown in Table 4.

Most of the ENDF/B-VI fission product evaluations were done prior to 1980. During the last 10 years, 50 fission products were re-evaluated or extensively revised. ${ }^{3,4}$ For most of the revised evaluations the main emphasis was on the thermal and resolved resonance ranges. A number of the evaluations also have an unresolved resonance range which uses average resonance parameters. Thus, for the revised evaluations, the changes are generally for elastic, capture, and total cross sections below about $50 \mathrm{keV}$. The 18 new and 32 revised evaluations are shown in Table 5; the table indicates the "new" evaluations for ENDF/B-VI. The distinction between "new" and "revised" is somewhat subjective since a "new" evaluation may not be very different from the previous evaluation in some energy range (e.g. thermal and/or the resolved resonance range) and might give calculated results which would not differ appreciably from the previous evaluation. On the other hand, a "revised" evaluation might have a large change in, e.g. the thermal region, and thus calculated results could be quite different from the previous evaluation.

A major effort to evaluate many of the important actinides and structural elements was carried out in the 1980 's. In general the funding did not include any significant work for fission-product evaluations. Many of the ENDF/B-VI fission-product evaluations are identical to those of ENDF/B-V which was released in 1980. The need for better fission product cross-section data for specific applications has led 
to the revision of some of the fission-product evaluations. The criterion for deciding which fissionproduct evaluations were revised was based on review of the evaluation with attention given to the following:

1. were newer experimental data available?

2. if so, did the newer data differ significantly from the existing evaluation?

3. was there an urgent need to improve the evaluation for the specific fission-product nuclide for an existing application?

In many cases one of the main problems in analyzing fission-product data is the lack of good experimental data. The rule has always been to do the best you can with the limited data available. For the revised evaluations the main focus has been on the thermal and resolved energy ranges. The unresolved energy range was also done for some of the revised evaluations. In a number of cases, there have been new measurements of the capture cross section in the $\mathrm{keV}$ range and this has made it possible to improve the evaluation in that energy range.

In the past, many fission-product evaluations were done in a rather cursory fashion relative to the methods used for structural materials and the major actinides. The procedure for those evaluations included detailed fitting of the differential data, using SAMMY or some other similar code, for the resolved resonance range to rigorously determine resonance parameters. For the fission product evaluations resonance parameters were normally taken from the Mughabghab compilation ${ }^{5}$ or from some other similar source and, generally, no further analysis was done. The Mughabghab compilation is based on a review of the existing resonance parameters quoted in the literature. Exactly how the evaluated parameters are determined is not documented, as far as we can determine. The quality of the resonance parameters may vary considerably from one nuclide to another. For $Z>30$ the parameters given by Mughabghab are SLBW parameters unless otherwise indicated (see Ref. 5, Part B, page 51).

The reasons for the rather cursory methods used for the fission product evaluations include the following:

1. lack of good experimental data,

2. limited available funding,

3. limited manpower did not permit more detailed analysis, many evaluations needed to be completed,

4. time constraints limited what could be done, or

5. less accuracy needed, relative to actinides and structural materials.

A number of studies were done where the measured nuclide concentrations from burned fuel assemblies were compared with calculated values. This type of study can be (and generally is) a good test of the cross sections and fission-product yields. Generally good agreement between the measured and calculated values was obtained for a number of nuclides. About 30 different fission products were analyzed in this way. These studies were generally done for burnups of about $50 \mathrm{GWd} / \mathrm{MTU}$ or less. Several reports on this subject are available; some very recent work which indicates good agreement between measurements and calculations may be found in Ref. 6 .

There are about 30 fission products which account for most of the fission-product absorption in Light Water Reactor (LWR) spent fuel (e.g. 95\% of the FP absorption). For many of these important fission products the available data have been looked at more carefully. On the other hand, many fission products either have low absorption cross sections or very low yields and thus the absorption by that nuclide is not 
very significant. The "unimportant" fission products with low yields and/or low absorption cross sections have, in general, not been looked at very carefully since, as a rule, they do not have a significant impact on calculations.

The "top 20 fission products" as determined in Refs. $7-8$ are shown in Table 6. This determination is based primarily on the fraction of the total absorption rate in spent fuel for cooling times in the range 530 years. It should be recognized that fission products may be "important" for other reasons, such as shielding requirements, radioactivity, decay heat, or toxicity. There are at least 7 fission products which are considered to be "high priority" for these reasons: ${ }^{90} \mathrm{Sr},{ }^{90} \mathrm{Y},{ }^{106} \mathrm{Rh},{ }^{134} \mathrm{Cs},{ }^{137} \mathrm{Cs},{ }^{137} \mathrm{Ba}$, and ${ }^{144} \mathrm{Pr}$ (see Table 13 in Ref. 7).

Thirteen of the fission products in Table 6 were revised for previous versions of ENDF/B-VI (see Table 5) or have been revised in the present work (see Section 4). Five of the remaining 7 nuclides were revised in the work by Schenter et $\mathrm{al}^{2}$ (Table 4). The two remaining evaluations, ${ }^{131} \mathrm{Xe}$ and ${ }^{155} \mathrm{Gd}$, were done at Brookhaven National Laboratory (BNL) in 1978 and 1977, respectively. The seven fission products which have not been revised for ENDF/B-VI should be reviewed again, taking into account the possible existence of data that may have become available since 1980. Revised evaluations for these 7 nuclides may or may not be indicated.

A number of elements have very large thermal absorption cross sections and thus have been (or can be) used as burnable poisons and for reactivity control. Six of these have $Z$ numbers in the range from 63 to 77 and are shown in Table 7. All of the elements in Table 7 have been used for reactivity control or as burnable poisons with the possible exception of Ir. Iridium has about the same capture resonance integral as hafnium but the thermal absorption cross section is about four times as large. Iridium may be too expensive for most applications (the 1991 price was $\$ 16,000 / \mathrm{kg}$ ). Europium is also relatively expensive (1991 price was $\$ 7,500 / \mathrm{kg}$ ). Europium-oxide has been used in the control blades for the High Flux Isotopes Reactor (HFIR) at ORNL.

Hafnium is one of the elements that has been used in control rods and for reactivity control. For this reason there has been considerable interest in the cross sections of the six naturally occurring isotopes of hafnium. The hafnium isotopes were revised ${ }^{4}$ in 1992 and are included in ENDF/B-VI release 2. The revised hafnium evaluations are greatly improved relative to the previous ENDF/B-V evaluations and are considered to be adequate for most criticality safety applications. The revised evaluations do not include uncertainty files. This information would be very useful for some of the current applications involving hafnium.

Erbium-oxide has been used as a burnable absorber in PWRs by Combustion Engineering, Inc. (Ref. 9). The use of erbium in PWRs has several potential advantages relative to gadolinium or boron. One advantage for erbium is for the moderator temperature coefficient (MTC) in a PWR. This is achieved as the result of a strong double resonance in ${ }^{167} \mathrm{Er}$ at 0.460 and $0.584 \mathrm{eV}$. Other advantages of erbium-oxide as a burnable absorber are given in Ref. 9. Cross sections for ${ }^{168} \mathrm{Er}$ and ${ }^{170} \mathrm{Er}$ are available in the BROND (Russian) evaluated data library but are not available in ENDF/B-VI. Cross sections are also needed for ${ }^{169} \mathrm{Tm}$ (produced from beta decay of ${ }^{169} \mathrm{Er}$ ). Cross sections for ${ }^{169} \mathrm{Tm}$ are not available in any evaluated data file; cross sections for ${ }^{169} \mathrm{Tm}$ need to be added to ENDF/B-VI.'

Dysprosium-oxide has been used as a burnable absorber in advanced CANDU fuel designs (e.g. the 43-element CANFLEX design, Ref. 10). The thermal absorption cross section of dysprosium is 940 barns and the capture resonance integral is 1,480 barns (Ref. 5). The corresponding values for the element 
erbium are 160 barns for the thermal absorption cross section and 730 barns for the capture resonance integral (Ref. 5). The large absorption cross section of dysprosium is primarily due to the ${ }^{164} \mathrm{Dy}$ isotope which has an absorption cross section of 2,650 barns. Revised evaluations for the dysprosium isotopes are discussed in Section 4.

There has been considerable discussion recently about potential criticality applications with an intermediate flux spectrum. For such applications, it might be useful to use absorbers with a relatively large absorption cross section in the $\mathrm{keV}$ range. The use of europium is a possibility for such applications. Four of the Eu isotopes $\left({ }^{151} \mathrm{Eu},{ }^{152} \mathrm{Eu},{ }^{153} \mathrm{Eu}\right.$, and ${ }^{154} \mathrm{Eu}$ ) have large absorption cross sections in the $\mathrm{keV}$ range. Europium-151 and -152 appear to have the largest values (of all the tabulated data given) for the Maxwellian-averaged neutron capture cross sections at $\mathrm{kT}=30 \mathrm{keV}$ (Ref. 11). Europium151 and -153 are the naturally occurring isotopes; ${ }^{152} \mathrm{Eu}$ and ${ }^{154} \mathrm{Eu}$ are produced by capture reactions. Europium-154 and -155 are important fission products in PWR and BRW burnup and strongly influence the production of ${ }^{155} \mathrm{Gd}$, one of the most important fission products.

\subsection{REVIEW OF ENDF/B-VI FISSION PRODUCT-PRODUCT CROSS SECTIONS FOR THE FAST ENERGY RANGE (LANL)}

The goal for this work has been to review the current status of the fission product evaluations available from ENDF/B-VI and other libraries of evaluated nuclear data. The results of this review will be used to define a program for improving the evaluations through new calculations, utilization of experimental results which have become available since the current evaluation was done and, if needed, new experiments. The thermal capture in several evaluated libraries has been reviewed as compared to experiment. Many graphical comparisons between the different libraries have been done. A survey of new experimental data measured since 1975 (the date when the majority of the ENDF/B-VI evaluations were done) has also been performed. Examples of the graphical comparison and data surveys are given below. And finally, there is a discussion of the possibilities of making new nuclear-model calculations for fission-product nuclides with recently improved nuclear models.

\section{Integral Comparisons}

The thermal absorption cross section is a good measure for the effectiveness of influencing normal aqueous (thermal spectrum) systems. Tables were prepared comparing ENDF/B-VI, JENDL-3.2, BROND, and CENDL evaluated thermal capture values. A section of this table is shown in Table 8 for Te through $\mathrm{Lu}, Z=52$ to 71 ). In the table, the evaluated value that agrees best with the experimental value is highlighted. JENDL-3.2 is quite good overall, but in many cases, one of the other libraries is closer o: almost as close.

\section{Graphical Comparisons}

For thermalized systems, the most interesting comparison is for the capture cross section. This comparison is of most interest to the ORNL component (resolved and unresolved resonance regions) of this program. For dry criticality (spectrum in the keV-MeV range), the inelastic cross section begins to be important also, and this is where the modeling expertise of the Los Alamos National Laboratory (LANL) $\mathrm{T}-2$ group can contribute the most. From various data sources, a large number of graphs of both capture and inelastic cross sections have been made. Examples of comparisons are shown in Figs. 2, 3, and 4. 


\section{Available Experimental Data}

The high-energy portion of most of the current ENDF/B-VI fission-product file was done by Schenter and Schmittroth in 1974. In order to see what new data might now be available to improve the fissionproduct evaluations, a survey of the CSISRS library for experiments done since 1975 was performed. A file with 3790 lines of such experiments was prepared. A sample region shows that some high-energy reactions are included, which will help to verify the performance of the new modeling results. Table 9 gives the experimental data files for the capture cross section for 8 isotopes of samarium which are available in the CSISRS library. The table includes only experiments published since 1975 . There are no measurements of the capture cross sections of ${ }^{151} \mathrm{Sm}$ (half-life $=90$ years). Samarium-151 is an important fission product for thermal systems (rank $=5$ in Table 6) and also for fast systems (rank $=9$, see discussion in Section 5 of this report). Graphical comparisons for ${ }^{147} \mathrm{Sm}$ capture, ${ }^{149} \mathrm{Sm}$ capture, ${ }^{152} \mathrm{Sm}$ capture, ${ }^{154} \mathrm{Sm}$ capture, and ${ }^{154} \mathrm{Sm}$ high energy capture are shown in Figs. 5 to 9.

\section{Theory Work on Fission Products}

Oak Ridge National Laboratory has taken the responsibility for improving the resonance capture treatment. The LANL T-2 group is interested in extending the ORNL work from $1 \mathrm{keV}$ up, and also working on other isotopes for which the ENDF/B-VI data are either weak or missing. The inelastic data are especially important in cases where the capture cross section is small, which occurs particularly for the even-mass isotopes of fission products such as $\mathrm{Zr}, \mathrm{Mo}, \mathrm{Ru}, \mathrm{Pd}, \mathrm{Nd}$, and $\mathrm{Sm}$.

\section{International Cooperation}

Advantage is taken of related programs in the international arena, such as the Nuclear Energy Agency's Working Party on International Evaluation Cooperation (Subgroup 10). Some integral measurements indicate differences varying between 0.4 and 1.2 in $\mathrm{C} / \mathrm{E}$ for weakly absorbing fission products.

\section{LANL T-2 Approach for Model Calculations}

The inelastic scattering process is comprised of two contributions: the compound nucleus, and the direct components. Most of the older ENDF/B-VI evaluations included only the compound nucleus component, using the Hauser-Feshback COMNUC code.

Recent work performed by Gruppelaar, Koning, Chiba, and others pointed to the importance of direct reactions, and in some cases a clear need for a coupled channels calculation, rather than DWBA, has been perceived. This manifests itself in the shape of the inelastic excitation function as it rises from threshold. Direct contributions are also particularly important at incident energies above the peak of the inelastic excitation function, where the compound contribution falls off more rapidly.

Over the years, LANL has developed the GNASH code to calculate nuclear reactions, including inelastic scattering. At low energies, before multiparticle emission becomes important, the COMNUC code is often used. Width fluctuation processes, which are important in compound nucleus decay at low energies, are included with the Moldauer formalism. The width fluctuation correction factors are needed to correct a problem in the Hauser-Feshbach theory where the compound elastic scattering is underpredicted and the inelastic scattering is typically overpredicted. 
Width fluctuation effects in compound nucleus reactions have recently been studied with a view to improving the computational tools for calculating elastic and inelastic scattering. The differing theoretical approaches due to Moldauer, Hofmann et al, Weidenmuller et al, Herman et al, have been studied to assess their theoretical rigor and their suitability for numerical implementation. The preliminary conclusion is that the Hofmann-Richert-Tepel-Weidenmuller (HRTW) approach may be the most suitable for inclusion into the LANL codes.

A new project in the LANL T-2 group to include features of COMNUC and GNASH into a single new reaction code will include these width-fluctuation effects. This new code, along with the coupledchannels ECIS code, will be a valuable tool for the evaluation of fission-product inelastic scattering.

\subsection{REVISED EVALUATIONS OF FISSION PRODUCT CROSS SECTIONS}

Revised cross-section evaluations for 13 fission-product nuclides were performed. Elastic, capture, and total cross sections are revised. Newer experimental data not considered for ENDF/B-VI were used. Primary emphasis was placed on the resolved and unresolved resonance regions. The resolved resonance range was extended to higher energies and the number of resonances was increased. In the unresolved resonance region the parameters were either revised or, for some nuclides, added to the file. The revised capture cross sections are based on measured data for the energy range 3-700 keV (unresolved resonance range and above). The revised evaluations are available in ENDF/B-VI format.

This section discusses the revised cross-section evaluations for ${ }^{134} \mathrm{Cs},{ }^{135} \mathrm{Cs},{ }^{134} \mathrm{Ba},{ }^{149} \mathrm{Sm},{ }^{154} \mathrm{Eu}$, ${ }^{155} \mathrm{Eu},{ }^{160} \mathrm{Dy},{ }^{161} \mathrm{Dy},{ }^{162} \mathrm{Dy},{ }^{163} \mathrm{Dy},{ }^{164} \mathrm{Dy},{ }^{175} \mathrm{Lu}$, and ${ }^{176} \mathrm{Lu}$. The evaluations for ${ }^{134} \mathrm{Ba},{ }^{154} \mathrm{Eu}$, and ${ }^{155} \mathrm{Eu}$ were previously revised ${ }^{3}$ for ENDF/B-VI; the other eight evaluations, carried over from ENDF/B-V, were completed in the 1974-1980 time period. The evaluations for the dysprosium isotopes go back to ENDF/B-IV. Newer experimental data, not considered for the current ENDF/B-VI evaluations, were used in all of the revised evaluations. The primary emphasis was placed on the resolved and unresolved resonance regions, but newer measured data were also used for energies above the unresolved resonance region. Elastic, capture, and total cross sections are revised. Some important parameters from the revised evaluations are given in Table 10; corresponding values from the ENDF/B-VI evaluations are also given. Table 11 shows the number of points, generated by NJOY, for each of the revised evaluations. The unresolved resonance parameters for the revised evaluations are shown in Table 12. The thermal capture cross sections and capture resonance integrals from the revised evaluations are compared with the corresponding ENDF/B-VI values in Table 13.

\section{Changes for Revised Evaluations}

The ENDF/B-VI ${ }^{134} \mathrm{Ba}$ evaluation ${ }^{3}$ used the resolved resonance parameters from Mughabghab. ${ }^{5}$ The revised evaluation is based on measured data ${ }^{12}$ taken at ORELA. Analysis of the measured data was performed with SAMMY ${ }^{13}$ to obtain Reich-Moore resonance parameters. The thermal capture cross section was revised ${ }^{14}$ and the unresolved resonance range was added. The total cross section for the revised evaluation is shown in Fig. 10 . The revised ${ }^{134} \mathrm{Ba}$ evaluation should be a big improvement over the ENDF/B-VI evaluation.

Samarium-149 accounts for a large fraction of the fission-product absorption rate because of its very large thermal absorption cross section. In this revision the number of resolved resonances is increased 
from 30 to 159 , the upper limit of the resolved resonance range is increased from 100 to $502 \mathrm{eV}$, and the unresolved resonance range is revised. The resolved resonance parameters are taken from the Mughabghab compilation. The capture cross section for the revised ${ }^{149} \mathrm{Sm}$ evaluation ${ }^{15}$ is shown in Fig. 11 .

The ENDF/B-VI evaluations for ${ }^{154} \mathrm{Eu}$ and ${ }^{155} \mathrm{Eu}$ were revised ${ }^{3}$ in 1989 . Cross sections for these isotopes are of considerable importance because ${ }^{155} \mathrm{Eu}$ is radioactive with a half-life of 4.75 years and decays to ${ }^{155} \mathrm{Gd}$, which is stable. Gadolium- 155 has a thermal absorption cross section of 60,900 barns. A few years after discharge ${ }^{155} \mathrm{Gd}$ is one of the most important nuclides in spent reactor fuel because of its very high absorption rate. The ${ }^{155} \mathrm{Gd}$ concentration in spent fuel depends heavily on the ${ }^{155} \mathrm{Eu}$ concentration at reactor shutdown. For this reason it is important to determine the ${ }^{155} \mathrm{Eu}$ concentration and absorption rate as accurately as possible. Burnup calculations show that the calculated ${ }^{154} \mathrm{Eu}$ and ${ }^{155} \mathrm{Eu}$ concentrations are not in good agreement with measured values. The ${ }^{154} \mathrm{Eu}$ and ${ }^{155} \mathrm{Eu}$ cross sections are most likely the reason for the disagreement between the calculated and measured concentrations. The parameters of the negative (bound) and first positive resonance have been revised for both ${ }^{154} \mathrm{Eu}$ and . ${ }^{155} \mathrm{Eu}$. The thermal capture cross section of ${ }^{154} \mathrm{Eu}$ is increased from 1357 to 1846 barns and the capture resonance integral for ${ }^{155} \mathrm{Eu}$ is reduced from 23,445 to 15,300 barns. These changes are in agreement with measured data from Sekine. ${ }^{16}$ The revised capture cross sections for ${ }^{154} \mathrm{Eu}$ and ${ }^{155} \mathrm{Eu}$ are compared with the ENDF/B-VI values in Figs. 12 and 13. Burnup calculations done at ORNL indicate that the revised evaluations for ${ }^{154} \mathrm{Eu}$ and ${ }^{155} \mathrm{Eu}$ will result in better agreement with measured values.

Cross sections for dysprosium are of interest because of the relatively large thermal capture cross section. The main isotope contributing to the large Dy capture cross section is ${ }^{164}$ Dy with a thermal capture cross section of about 2650 barns. The ENDF/B-VI evaluations for the dysprosium isotopes were done in 1974. For this revision the resolved resonance parameters are taken from the Mughabghab ${ }^{5}$ compilation; the upper limit of the resolved resonance range and the number of resolved resonances have been increased. For ${ }^{164} \mathrm{Dy}$ the unresolved resonance range was revised; for ${ }^{160} \mathrm{Dy},{ }^{161} \mathrm{Dy}$, and ${ }^{162} \mathrm{Dy}$ an unresolved resonance range has been added; unresolved parameters are not given for ${ }^{163}$ Dy. For the energy range 3 to $700 \mathrm{keV}$, the capture cross sections in the revised evaluations are based on measured data. The ${ }^{160}$ Dy evaluated capture is compared with the measured data of Beer ${ }^{17}$ in Fig. 14 and the ${ }^{162} \mathrm{Dy}$ capture cross section above $20 \mathrm{keV}$ is compared with the measured data of Kononov ${ }^{18}$ in Fig. 15. The capture cross sections from the revised evaluations for ${ }^{161}$ Dy and ${ }^{164}$ Dy are shown in Figs. 16 and 17 , respectively. The total cross section for the revised ${ }^{163}$ Dy evaluation is shown in Fig. 18.

Revised evaluations for ${ }^{175} \mathrm{Lu}$ and ${ }^{176} \mathrm{Lu}$ were also done. For both isotopes the upper limit of the resolved resonance range and the number of resolved resonances were increased. The unresolved resonance parameters were also revised for both isotopes. For ${ }^{175} \mathrm{Lu}$ the capture cross section for the energy range $3 \mathrm{keV}$ to $2 \mathrm{MeV}$ is based on the measured data of Macklin. ${ }^{19}$ The ${ }^{176} \mathrm{Lu}$ capture cross section for the energy range 3-700 keV is based on the measured data of Beer. ${ }^{16}$ The total cross section for the revised ${ }^{175} \mathrm{Lu}$ evaluation is shown in Fig. 19. The capture cross section for the revised ${ }^{176} \mathrm{Lu}$ evaluation is shown in Fig. 20 . Also shown is the measured ${ }^{176} \mathrm{Lu}$ capture cross section. ${ }^{16}$

Revised evaluations for ${ }^{134} \mathrm{Cs}$ and ${ }^{135} \mathrm{Cs}$ were also done as part of this work. For ${ }^{134} \mathrm{Cs}$ the resolved resonance range was revised and the unresolved resonance range was added to the evaluation. The thermal capture cross section is 139.6 barns, compared to the Ref. 5 value of $140 \pm 12$ barns. The capture resonance integral is 102 barns. The value given in Ref. 5 is 54.2 barns, but this is the value calculated from the resolved resonance parameters and not an experimentally measured value; thus it must be considered as only a lower limit for the resonance integral. For ${ }^{135} \mathrm{Cs}$ the current ENDF/B-VI evaluation 
does not have resolved resonance parameters (see Table 1). Both a resolved resonance region ( $1.0 \mathrm{e}-5 \mathrm{eV}$ to $180 \mathrm{eV})$ and an unresolved region $(180 \mathrm{eV}$ to $10 \mathrm{keV})$ were added for the revised evaluation. The thermal capture cross section was reduced from 8.70 barns to 8.45 barns and the capture resonance integral was reduced from 65 barns to 50 barns. The revised capture cross sections for ${ }^{134} \mathrm{Cs}$ and ${ }^{135} \mathrm{Cs}$ are compared with the corresponding ENDF/B-VI evaluations in Figs. 2 land 22, respectively. Both ${ }^{134} \mathrm{Cs}$ and ${ }^{135} \mathrm{Cs}$ are included in the PWR and BWR burnup calculations (see Refs. 6-8); currently the impact of the revised evaluations has not been tested.

The compilation of Maxwellian-averaged neutron capture cross sections at $\mathrm{kT}=30 \mathrm{keV}$ (Ref. 11) was mentioned in Section 2. The tables compiled by Bao and Kappeler, ${ }^{11}$ published in 1987, include measurements up to about 1985 , so that the information is more up to date than most of the current ENDF/B-VI fission product evaluations. For the ENDF/B-VI evaluations which have been updated since 1987, the Maxwellian-averaged values from the revised evaluations are generally consistent with the Ref. 11 values. In a few cases there have been new measurements since 1987. Table 14 compares the Maxwellian-averaged capture cross sections for the 13 revised fission-product evaluations with the ENDF/B-VI evaluation and with measured values. The references $(11-12,16-20)$ for the measured values are shown in the last column of the table. In the case of ${ }^{134} \mathrm{Cs},{ }^{135} \mathrm{Cs}$, and ${ }^{154} \mathrm{Eu}$ there are no measurements; for these nuclides theoretical calculations have been used (see Ref. 11 for discussion). Maxwellian-averaged capture cross sections are of considerable interest for applications in astrophysics and astronomy. They are also a convenient way to compare capture cross sections in the keV range (about $1 \mathrm{keV}$ to $1 \mathrm{MeV}$ energy). Note that the values for the revised evaluations differ from the previous ENDF/B-VI values by factors between 0.5 and 3. Nine of the 13 nuclides in Table 14 have changed by significant amounts. It would be very worthwhile to compare values for the current and revised ENDF/BVI evaluations with the other ENDF/B-VI format evaluations (e.g. JEF-2.2, JENDL-3.2, etc.).

\section{Conclusions for Section 4.0}

The discussion in Sections 1-4 indicates that improved fission-product evaluations utilizing both differential and integral data are needed. For ${ }^{134} \mathrm{Ba}$ the resolved resonance parameters were determined by fitting the experimental data using SAMMY. ${ }^{13}$ Resolved resonance parameters from Mughabghab ${ }^{5}$ were used for the other 12 nuclides considered. For energies above the resolved resonance region the revised capture cross sections are based on measured data. ${ }^{16-18}$ When new, high quality differential data for these nuclides are available it should be utilized to perform new evaluations. These revised evaluations represent a significant improvement over the ENDF/B-VI evaluations currently in use.

\subsection{STATUS OF FISSION-PRODUCT CROSS SECTIONS FOR FAST REACTORS}

Subgroup 17 of the Working Party on Evaluation Co-Ordination (WPEC) of the Nuclear Energy Agency (NEA) of the Organization for Economic Co-Operation and Development (OECD) has investigated the status of fission-product evaluations for fast reactor applications. The final report of Subgroup 17 is given in NEA/WPEC-17 (Ref. 21). The reader is referred to Ref. 21 for the complete details of the work. The participants were Commissariat a l'Energie Atomique (CEA-France), Energy Research Foundation (ECN-the Netherlands), Institute of Physics \& Power Engineering (IPPE-Russian Federation), and Joint Contribution of Toshiba Corporation, the Japan Atomic Energy Research Institute (JNDC_- Japan). The Cross Section Evaluation Working Group (CSEWG, USA) did 
not participate in the project. This was very regrettable, since comparisons of the ENDF/B-VI fissionproduct cross sections with other ENDF/B-6 format evaluations can be very useful.

The JEF-2.2 (CEA and ECN), JENDL (JNDC), FOND-2.1 (IPPE), and ADL-3 (IPPE) libraries were included in the analysis. The pointwise neutron weighting function used in the analysis was based on a typical fast reactor and is shown in Fig. 23. This weight function was used to generate one-group averaged capture $(M T=102)$, inelastic scattering $(M T=4)$, and $(n, 2 n)(M T=16)$ cross sections for about 130 fission-product nuclides. The comparisons for $\mathrm{MT}=102, \mathrm{MT}=4$, and $\mathrm{MT}=16$ are given in Tables 5.1, 5.2 , and 5.3, respectively of Ref. 21 .

The NJOY Nuclear Data Cross Section code system was used to generate one-group total, elastic, inelastic, and capture cross sections using the neutron weighting function shown in Fig. 23. Of special interest are the 13 revised fission-product evaluations discussed in Section 4.0. The one-group average fission-product cross sections for these nuclides are shown in Table 15. One-group average fissionproduct cross sections for 16 additional nuclides are given in Table 16. Tables 15 and 16 include all of the "top 20 ENDF/B-VI fission products" discussed in Section 2.0 and listed in Table 6. It should be understood that the nuclides included in Table 6 were ranked according to the absorption rate in spent LWR reactor fuel. The absorption rates for fast reactors are somewhat different; as a result, the ranking for fast reactors is different. For example, the importance (rank) for ${ }^{101} \mathrm{Ru}$ is much higher relative to the rank shown in Table 6 . Table 5.1 of Ref. 21 indicates that ${ }^{101} \mathrm{Ru}$ is the most important fission product as determined by the product of the cross section and yield of the nuclide. Other important fission-product nuclides (for fast reactors), not included in Tables 15 and 16 , include ${ }^{105} \mathrm{Pd},{ }^{107} \mathrm{Pd},{ }^{147} \mathrm{Pm},{ }^{103} \mathrm{Ru},{ }^{97} \mathrm{Mo}$, ${ }^{102} \mathrm{Ru},{ }^{104} \mathrm{Ru}$, and ${ }^{141} \mathrm{Pr}$ with rank varying from 2 to 20 in Table 5.1, Ref. 21.

One-group average fission-product capture cross sections for the revised ENDF/B-VI evaluations discussed in Section 4.0 are compared with the corresponding JEF-2.2 and JENDL-3.2 values in Table 17. Some of the JEF-2.2 and JENDL-3.2 values are not included in Table 17. The JENDL-3.2 file does not have evaluations for the dysprosium and lutetium isotopes. Other JEF-2.2 values were not included in Table 5.1 of Ref. 21 because their importance was below the cutoff value (not in the top 130 nuclides). The ENDF/B-VI one-group average fission-product capture cross sections for the 16 nuclides given in Table 16 are compared with the corresponding JEF-2.2 and JENDL-3.2 values in Table 18. The reader should note that ${ }^{15 l} \mathrm{Eu}$ is also a "shielded" nuclide (see Section 2.0 for discussion of "shielded"), thus the JEF-2.2 and JENDL-3.2 values are not given in Table 18.

The one-group average capture cross section in Table 17 can be compared with the corresponding $30 \mathrm{keV}$ Maxwellian averaged capture cross sections given in Table 14. The Table 17 values should be compared with the revised (column 4) values in Table 14. Note that the Table 14 values are given in mb, not barns as in Table 17. The average capture cross sections in Table 17 are $5.4 \%$ higher than the corresponding values in Table 14. The values in Table 17 vary from $13 \%$ lower to $26 \%$ higher relative to the corresponding values in Table 14 . The two extreme cases are ${ }^{134} \mathrm{Ba}\left(13 \%\right.$ lower) and ${ }^{149} \mathrm{Sm}(26 \%$ higher). For the other 11 nuclides values agree to within $13 \%$ or less; also only 2 of the 13 values in Table 17 are lower than the corresponding Table 14 values, while 11 of 13 are higher. The most important conclusion is that the one-group average fission-product cross sections using the fast reactor weight function (Table 17) are generally only slightly different from the $30 \mathrm{keV}$ Maxwellian-averaged capture cross sections (Table 14). This is very important since comparison of the $30 \mathrm{keV}$ Maxwellianaveraged capture cross sections from a given evaluation, with the corresponding measured value, will also give an indication of the accuracy of the evaluation for fast reactor applications. 


\section{Comparisons of One-Group Average Capture Cross Sections}

Average cross sections from JEF-2, JENDL-3.2, and ENDF/B-VI compilations are shown in Table 17. The values shown for ENDF/B-VI are from the revised evaluations discussed in Section 4.0. The ENDF/B-VI (revised) value for ${ }^{134} \mathrm{Ba}$ is $26 \%$ lower than the corresponding JENDL-3.2 value. Since the production of ${ }^{134} \mathrm{Ba}$ is shielded from the beta decay chain by the stable ${ }^{134} \mathrm{Xe}$ the concentration and thus the absorption rate is very small. The rank given in Table 5.1 of Ref. 21 for ${ }^{134} \mathrm{Ba}$ is 130 , thus it is not an important fission product. The capture cross section of ${ }^{134} \mathrm{Ba}$ is of considerable interest for use in the sprocess application for astrophysics. We also note that the revised capture cross section is based on the work of Koehler et al. (Ref. 12). Europium-154 is also shielded from beta decay by the stable ${ }^{154} \mathrm{Sm}$, however it is produced by the neutron capture reaction on ${ }^{153} \mathrm{Eu}$. Note that the revised ENDF/B-VI value is in good agreement with the ADL-3 library (IPPE). There is no experimental data for ${ }^{155}$ Eu capture above $33 \mathrm{ev}$ and the JENDL-3.2 capture is about a factor of 2 smaller than JEF-2.2. The revised ENDF/B-VI value is higher than JENDL-3.2 by a factor of 1.13 and is based on the measurement by $\mathrm{Jaag}^{20}$ shown in Table 14 ( $30 \mathrm{keV}$ Maxwellian average).

The one-group average fission-product capture cross sections in Table 18 are in generally good agreement with a few exceptions. The ENDF/B-VI value for ${ }^{131} \mathrm{Xe}$ is about $20 \%$ lower than the corresponding JENDL-3.2 value. There are no experimental capture cross-section data in the keV range. On page 85 of Ref. 21 attention is called to the missing level effect below about $4 \mathrm{keV}$ in the ENDF/B-VI evaluation; this is also apparent from the plot on page 105 of Ref. 21 . The one-group average capture cross seciions for ${ }^{151} \mathrm{Sm}$ vary from 2.1080 barns (JENDL-3.2) to 3.3618 barns (JEF-2.2). The ENDF/BVI value, 2.9430 barns, is about $40 \%$ higher than JENDL-3.2. There are no experimental capture crosssection data for ${ }^{151} \mathrm{Sm}$ in the keV energy range and the various evaluations differ considerably between $1 \mathrm{keV}$ and $10 \mathrm{MeV}$. New measurements of the capture cross sections and/or additional evaluation work would be desirable for both ${ }^{131} \mathrm{Xe}$ and ${ }^{151} \mathrm{Sm}$. It should be noted that the half-life of ${ }^{151} \mathrm{Sm}$ is about 90 years.

Based on the limited scope of the work discussed in this section, it is difficult to say very much about the status of fission-product evaluations other than what has already been stated in Ref. 21 . Clearly more comparisons of other ENDF/B-VI fission-product evaluations with JEF-2.2, JENDL-3.2, and BROND-2 evaluations would be useful with particular emphasis on the fission-products that have the highest rank for fast reactor applications. Results for about 30 additional ENDF/B-VI fission products would be desirable. In addition, it seems clear that the ENDF/B-VI evaluations for ${ }^{131} \mathrm{Xe}$ and ${ }^{151} \mathrm{Sm}$ should be reviewed and possibly revised.

\subsection{SUMMARY AND CONCLUSIONS}

This report was written to review and summarize the status of the current ENDF/B-VI fissionproduct nuclide evaluations and to make recommendations on how to improve the situation. In this section we will give the summary and conclusions for the work and suggest ways to improve the current evaluations. The content of this report has strongly emphasized needs for criticality safety applications but other applications have also been considered. The goal for ENDF/B-VI evaluations should be to produce a general purpose file that is adequate for all applications. We will now review and summarize the most important topics that have been discussed in previous sections. 


\section{Resolved Resonance Region}

Current ENDF/B-VI fission product evaluations use either the SLBW or MLBW resonance parameter formalism or, for about $30 \%$ of the evaluations, cross sections are given in pointwise form. Resonance parameters are available for several fission-product nuclides which are currently given as pointwise evaluations in ENDF/B-VI. The following ENDF/B-VI evaluations, identified in Section 2.0, do not have resolved resonance parameters- ${ }^{93} \mathrm{Zr},{ }^{18} \mathrm{Pd},{ }^{136} \mathrm{Xe},{ }^{135} \mathrm{Cs},{ }^{140} \mathrm{Ce},{ }^{142} \mathrm{Ce}$, and ${ }^{148} \mathrm{Sm}$. A revised evaluation for ${ }^{135} \mathrm{Cs}$ with MLBW parameters is now available and was discussed in Section 4 . The other nuclides listed above should be revised to include resolved resonance parameters. There may be other nuclides, not identified in this report, which should also be revised to include resolved resonance parameters. In addition, some of the current evaluations may need to be revised; e.g. ${ }^{131} \mathrm{Xe}$ which appears to suffer from the missing level effect below $4 \mathrm{keV}$, see discussion given in Section 5; there are likely several other such evaluations.

\section{Unresolved Resonance Region}

Very few of the ENDF/B-V fission-product evaluations had unresolved resonance parameters. Many of the JENDL-3.2 fission-product evaluations have included unresolved parameters. Unresolved resonance parameters are recommended for any new or revised evaluations. The ENDF/B-VI fissionproduct evaluations with unresolved resonance parameters are shown in Table 2 . Currently the number of ENDF/B-VI fission-product evaluations with unresolved parameters is 30. The ENDF/B-VI unresolved parameters for ${ }^{99} \mathrm{Tc}$ are compared with the corresponding parameters from other evaluations in Table 3 . There is considerable variation between the various evaluations for ${ }^{99} \mathrm{Tc}$ and this is also generally true for other evaluations as well. For some ENDF/B-V evaluations, a non-zero file 3 pointwise background was sometimes used in the unresolved resonance range. The current ENDF/B-VI evaluation for ${ }^{99} \mathrm{Tc}$ has a non-zero background in the unresolved range. The unresolved resonance parameters for ${ }^{99} \mathrm{Tc}$ need to be revised and the non-zero $\mathrm{MF}=3$ contribution eliminated.

\section{General Discussion}

Evaluations ${ }^{2}$ for fission product capture cross sections for 36 nuclides, revised in 1980, for ENDF/B$\mathrm{V}$ are shown in Table 4. New and revised evaluations for 50 fission-product evaluations for ENDF/B-VI up to about 1993 are shown in Table 5. The "top 20" ENDF/B-VI fission products, based on information in Refs. 7-8, are given in Table 6. Elements with large thermal absorption cross sections are shown in Table 7. Two important applications include the use of erbium-oxide and dysprosium-oxide as burnable absorbers (see discussion on page 6). ENDF/B-VI has evaluations for ${ }^{166} \mathrm{Er}$ and ${ }^{167} \mathrm{Er}$; evaluations for the other four stable erbium isotopes, ${ }^{162} \mathrm{Er},{ }^{164} \mathrm{Er},{ }^{168} \mathrm{Er}$, and ${ }^{170} \mathrm{Er}$ are not included. The additional isotopes of erbium are available in the BROND-2.2 (Russian) evaluated data file. Evaluations for the other four erbium isotopes should be added to the ENDF/B-VI file. Either new evaluations are needed or perhaps one or more of the BROND-2.2 evaluations could be used. An evaluation for ${ }^{169} \mathrm{Tm}$ (stable) is also needed; this nuclide is produced by beta decay of ${ }^{169} \mathrm{Er}$ (9.40 days) which in turn is produced by the ${ }^{168} \mathrm{Er}$ (n,gamma) reaction. Evaluations for ${ }^{170} \mathrm{Tm}$ and ${ }^{171} \mathrm{Tm}$ would be desirable but may not be feasible due to the short half-lives, 128.6 days and 1.92 years, respectively. A good review of the status of fissionproduct cross sections for the fast energy range was given in Section 3. Revised cross-section evaluations for 13 fission-product nuclides were done as part of the current project and are described in Section 4 and the details are shown in Tables 10 to 14 and Figs. 10 to 22 . Europium-154 and -155 are important fission products for PWR and BWR burnup and strongly influence the production of ${ }^{155} \mathrm{Gd}$, one of the most 
important fission products. Burnup calculations done at ORNL indicate that the use of the revised evaluations for ${ }^{154} \mathrm{Eu}$ and ${ }^{155} \mathrm{Eu}$ will result in better agreement between the calculated and measured concentrations of these nuclides. Another very important fission product is ${ }^{149} \mathrm{Sm}$ with a rank of number 4 in Table 6. We do not expect that the revised ${ }^{149} \mathrm{Sm}$ evaluation will have a large effect on the ${ }^{149} \mathrm{Sm}$ absorption rate but burnup calculations using the revised revaluation have yet to be done.

\section{Status of Fission-Product Cross Sections for Fast Reactors}

One-group average fission-product for 29 nuclides were generated using the typical fast reactor weight function shown in Fig. 23. Total, elastic, inelastic, and capture cross sections were obtained and are shown in Tables 15 and 16. One-group average capture cross sections for the revised ENDF/B-VI evaluations (Table 17) and for ENDF/B-VI (Table 18) are compared with the corresponding JEF-2.2 and JENDL-3.2 evaluations. The one-group average capture cross sections in Table 18 are in generally good agreement with a few exceptions. Results for about 30 additional ENDF/B-VI fissions products would be highly desirable. This would permit us to do comparisons for the fission-product nuclides which are important for fast reactor applications. It seems clear that the ENDF/B-VI evaluations for ${ }^{131} \mathrm{Xe}$ and ${ }^{151} \mathrm{Sm}$ should be further reviewed and possibly revised.

\section{Summary of Recommendations}

A number of recommendations have been made in this report. The most important of these are summarized in Table 19. The top 20 fission products as determined by the absorption rate in LWR spent fuel were shown in Table 6 . The current status and our recommendations for these specific fissionproduct nuclides are given in Table 20 . Nuclides are listed in order of decreasing rank as determined by the absorption rate.

There has been no discussion of cross section uncertainties in this report. This is because there are no $\mathrm{ENDF} / \mathrm{B}-\mathrm{VI}$ uncertainty files for the range of nuclides considered, i.e. $Z=38$ to 77 . ENDF/B-V had uncertainty files for some materials but due to lack of funding there were essentially no uncertainty files included in ENDF/B-VI. This is considered to be a deficiency in the ENDF/B-VI files. The best and preferred way to do the uncertainty files is to include them as part of the original evaluation, e.g. using SAMMY to do both the basic evaluation and the uncertainty files as part of the basic evaluation. Trying to back-fit uncertainty files into an existing evaluation is generally an unsatisfactory approach. The need for uncertainty files for the hafnium evaluations was mentioned previously in section 2.0 of this report. Uncertainty files for the top 10-15 fission-products (see list in Table 6) would certainly be very desirable. 
Table 1. Fission-product nuclides which do not have resonance parameters.

\begin{tabular}{|c|c|}
\hline $36-K R-85(10.7 y)$ & $53-\mathrm{I}-130(12.4 \mathrm{~h})$ \\
\hline 37-RB- 86 (18.6d) & $53-\mathrm{I}-131(8.04 \mathrm{~d})$ \\
\hline $38-S R-89(50.5 d)$ & $53-\mathrm{I}-135(6.58 \mathrm{~h})$ \\
\hline 38-SR- 90 (29y) & $54-X E-133(5.25 d)$ \\
\hline $39-Y-90(64 h)$ & $54-\mathrm{XE}-135(9.10 \mathrm{~h})$ \\
\hline $39-Y-91(58.5 d)$ & 54-XE-136 \\
\hline 40-ZR- 93 (1.5My) & $55-\mathrm{CS}-135(3 \mathrm{My})$ \\
\hline $40-Z R-95(64 d)$ & $55-\mathrm{CS}-137(30.2 \mathrm{y})$ \\
\hline $41-N B-95$ (35d) & $56-\mathrm{BA}-140(12.76 \mathrm{~d})$ \\
\hline 42-MO- $99(66 \mathrm{~h})$ & $57-\mathrm{LA}-140(40.3 \mathrm{~h})$ \\
\hline 44-RU- 96 & 58-CE-140 \\
\hline 44-RU- 98 & $58-\mathrm{CE}-141(32.5 \mathrm{~d})$ \\
\hline 44-RU-103 (39d) & $58-\mathrm{CE}-142$ \\
\hline 44-RU-105 (35h) & $58-C E-143(33 h)$ \\
\hline $44-R U-106(373 d)$ & $58-C E-144(284 d)$ \\
\hline $45-\mathrm{RH}-105(35.4 \mathrm{~h})$ & 59-PR-142 (19.1h) \\
\hline $46-\mathrm{PD}-102$ & $59-P R-143$ (13.6d) \\
\hline 46-PD-110 & $61-\mathrm{PM}-148(5.37 \mathrm{~d})$ \\
\hline $47-A G-111(7.47 d)$ & $61-\mathrm{PM}-149(53.1 \mathrm{~h})$ \\
\hline 48-CD-115M (44.6d) & $61-\mathrm{PM}-151(28.4 \mathrm{~h})$ \\
\hline $50-\mathrm{SN}-123(129 \mathrm{~d})$ & $62-S M-148$ \\
\hline $50-\mathrm{SN}-125(9.63 \mathrm{~d})$ & $62-S M-153(46.7 \mathrm{~h})$ \\
\hline $50-\mathrm{SN}-126(0.25 \mathrm{My})$ & $63-E U-156(15.2 d)$ \\
\hline $51-\mathrm{SB}-124(60.2 \mathrm{~d})$ & $63-E U-157(15.2 \mathrm{~h})$ \\
\hline $51-\mathrm{SB}-125(2.76 \mathrm{y})$ & $65-\mathrm{TB}-160(72.4 \mathrm{~d})$ \\
\hline \multicolumn{2}{|l|}{$51-\mathrm{SB}-126(12.4 \mathrm{~d})$} \\
\hline \multicolumn{2}{|l|}{$52-\mathrm{TE}-120$} \\
\hline \multicolumn{2}{|l|}{$52-\mathrm{TE}-127 \mathrm{M}(109 \mathrm{~d})$} \\
\hline \multicolumn{2}{|l|}{ 52-TE-129M (33.4d) } \\
\hline $52-\mathrm{TE}-132(78.2 \mathrm{~h})$ & \\
\hline
\end{tabular}


Table 2. ENDF/B-VI Fission-Product Evaluations with Unresolved Resonance Parameters

Zr-91, Tc-99, Ru-101, Ru-102, Rh-103, Cd-106, Cd-108

Cd-110, Cd-1 12, Cd-113, Cd-114, Cd-116, Nd-143, Nd-145

Pm-147, Sm-144, Sm-147, Sm-149, Sm-150, Sm-152, Eu-151

Eu-152, Eu-153, Eu-154, Gd-152, Gd-154, Gd-155, Gd-157, Dy-164, Er-167

Table 3. Unresolved Parameters for $99-\mathrm{Tc}^{a}$

\begin{tabular}{||llllll||}
\hline PARM. & ENDF/B-VI & JENDL-3.2 & JEF-2.2 & BROND & BEIJING \\
S0 & 0.43 & 0.414 & 0.55 & 0.48 & 0.43 \\
S1 & 3.88 & 4.241 & 8.94 & 6.30 & NG \\
GW & 0.122 & 0.187 & 0.131 & -- & 0.160 \\
D0 & 12.12 & 20.59 & 18.34 & -- & 15.5 \\
GW/D0 & 100 & 90.8 & 71.7 & -- & 103 \\
R & 7.91 & 6.80 & 6.00 & NG \\
\hline $\begin{array}{l}\text { a Definitions of parameters } \\
\text { S0 s-wave strength function }\end{array}$ & & & \\
S1 p-wave strength function \\
GW capture width (eV) \\
D0 average s-wave level spacing (eV) \\
$\begin{array}{l}\text { GW/D0 in units of 10 } \\
\text { R scattering radius (fm) }\end{array}$ \\
\hline
\end{tabular}


Table 4. Fisssion Products Revised for ENDF/B-V R. E. Schenter, et al. (1980)

\begin{tabular}{|ll|}
\hline 42 & Mo-92, -94, -95, -96, -97,-98, \\
& Mo-100 \\
43 & Tc-99 \\
44 & Ru-100, -101, -102, -104 \\
45 & Rh-103 \\
\hline 46 & Pd-104, -105, -106, -107, -108, \\
& Pd-110 \\
47 & Ag-109 \\
53 & I-129 \\
\hline 55 & Cs-133 \\
57 & La-139 \\
59 & Pr-141 \\
60 & Nd-143,-144, -145, -146, -148 \\
& Nd-150 \\
\hline 61 & Pm-147 \\
62 & Sm-147, -149, -151, -152 \\
65 & Tb-159 \\
\hline
\end{tabular}

Table 5. ENDF/B-VI, New or Revised Evaluations

\begin{tabular}{|c|c|}
\hline \multicolumn{2}{|r|}{18 NEW EVALUATIONS FOR ENDF/B-VI } \\
\hline & $Y-89$ \\
\hline 41 & $\mathrm{Nb}-93$ \\
\hline 48 & $\begin{array}{l}\text { Cd-106, }-108,-110,-111,-112 \\
\text { Cd-113,-114,-116 }\end{array}$ \\
\hline 53 & $1-127$ \\
\hline 63 & Eu-151, -153 \\
\hline 67 & Ho-165 \\
\hline 75 & $\operatorname{Re}-185,-187$ \\
\hline 77 & Ir-191, -193 \\
\hline \multicolumn{2}{|r|}{$\begin{array}{l}32 \text { REVISED EVALUATIONS FOR } \\
\text { ENDF/B-VI }\end{array}$} \\
\hline 44 & $\mathrm{Ru}-101,-102$ \\
\hline 46 & Pd-105, -107 \\
\hline 55 & Cs-134 \\
\hline 56 & Ba-134, $-135,-136,-137,-138$ \\
\hline 60 & $\mathrm{Nd}-143,-145,-147$ \\
\hline 61 & Pm-147 \\
\hline 62 & Sm-144, $-147,-150,-151,-152$ \\
\hline 63 & Eu-152, $-154,-155$ \\
\hline 64 & Gd-152, -154 \\
\hline 68 & Er-166, -167 \\
\hline & $\begin{array}{l}\text { Hf- } 174,-176,-177,-178,-179 \\
\text { Hf- } 180\end{array}$ \\
\hline & $\begin{array}{l}\text { evaluations for Cs-134, Ba-134, Eu-154, } \\
\text { Eu-155 have been redone. The REVISED } \\
\text { uations will be considered for a new } \\
\text { ase of ENDF/B-VI, see Section } 4 \text { of this } \\
\text { it. }\end{array}$ \\
\hline
\end{tabular}


Table 6. Top 20 ENDF/B-VI Fission Products ${ }^{a}$

\begin{tabular}{|c|c|c|c|c|}
\hline & RANK $^{b}$ & YIELD $^{c}$ & $\begin{array}{l}\text { THERMAL } \\
\text { ABSORP (b) }\end{array}$ & $\begin{array}{l}\text { Resonance } \\
\text { Integral } \\
\text { (b) }\end{array}$ \\
\hline Mo-95 & 15 & 0.065 & 14.47 & 113.2 \\
\hline Tc-99 & 8 & 0.061 & 19.49 & 350.1 \\
\hline Ru-101 & 16 & 0.052 & 3.41 & 111.7 \\
\hline Rh-103 & 3 & 0.030 & 146.3 & 1,032 \\
\hline Ag-109 & 14 & 3.14 & 90.72 & 1,468 \\
\hline Xe-131 & 7 & 0.029 & 90.1 & 1,015 \\
\hline Cs-133 & 6 & 0.067 & 29.6 & 382.9 \\
\hline Cs- 135 & 22 & 0.065 & 8.70 & 65.0 \\
\hline Nd-143 & 2 & 0.060 & 323.1 & 129.6 \\
\hline Nd-145 & 11 & 0.039 & 41.9 & 229.7 \\
\hline Sm-147 & 12 & 0.022 & 57.0 & 790.0 \\
\hline Sm-149 & 4 & 0.011 & 39,700 & 3,264 \\
\hline $\mathrm{Sm}-150$ & 13 & & 103.4 & 337.8 \\
\hline $\mathrm{Sm}-151$ & 5 & $4.2-3$ & 15,210 & 3,438 \\
\hline Sm-152 & 9 & $2.7-3$ & 205.9 & 2,983 \\
\hline Eu-151 & 26 & & 9,170 & 3,364 \\
\hline Eu-153 & 10 & $1.6-3$ & 312 & 1,500 \\
\hline Eu-154 & 17 & & 1,352 & 1,345 \\
\hline Eu-155 & 23 & $3.2-4$ & 3,944 & 23,445 \\
\hline Gd-155 & 1 & & 60,930 & 1,552 \\
\hline \multicolumn{5}{|c|}{$\begin{array}{l}{ }^{a} \text { This table is based on information given in Refs. } 7-8 \text {. } \\
{ }^{b} \text { RANK is based on the absorption rate and is determined for } 3.0 \mathrm{wt} \\
\% \text { U-235, 30 GWd/MTU Burnup and } 10 \mathrm{yr} \text { cooling time (see } \\
\text { Ref. 8, page } 111 \text { ). } \\
{ }^{c} \text { Yield blank } \Longrightarrow \text { nuclide shielded from beta decay. }\end{array}$} \\
\hline
\end{tabular}


Table 7. Elements with Large Thermal Absorption Cross Sections

\begin{tabular}{||l|l|r|r|r||}
\hline & \multicolumn{1}{|c|}{$\begin{array}{c}\text { Absorption } \\
\text { (barns) }\end{array}$} & \multicolumn{1}{c|}{$\begin{array}{c}\text { RI } \\
\text { (barns) }\end{array}$} & \multicolumn{1}{c|}{$\begin{array}{c}\text { Price/kg } \\
(1991)\end{array}$} \\
\hline \hline 63 & europium (Eu) & 4565 & 2320 & $\$ 7500$ \\
\hline 64 & gadolinium (Gd) & 49000 & 390 & 485 \\
\hline 66 & dysprosium (Dy) & 940 & 1480 & 300 \\
\hline 68 & erbium (Er) & 160 & 730 & 650 \\
\hline 72 & hafnium (Hf) & 104 & 1992 & $200-1100$ \\
\hline 77 & iridium (Ir) & 425 & 2150 & 16000 \\
\hline
\end{tabular}


Table 8.

Capture cross section at $\mathbf{0 . 0 2 5 3}$

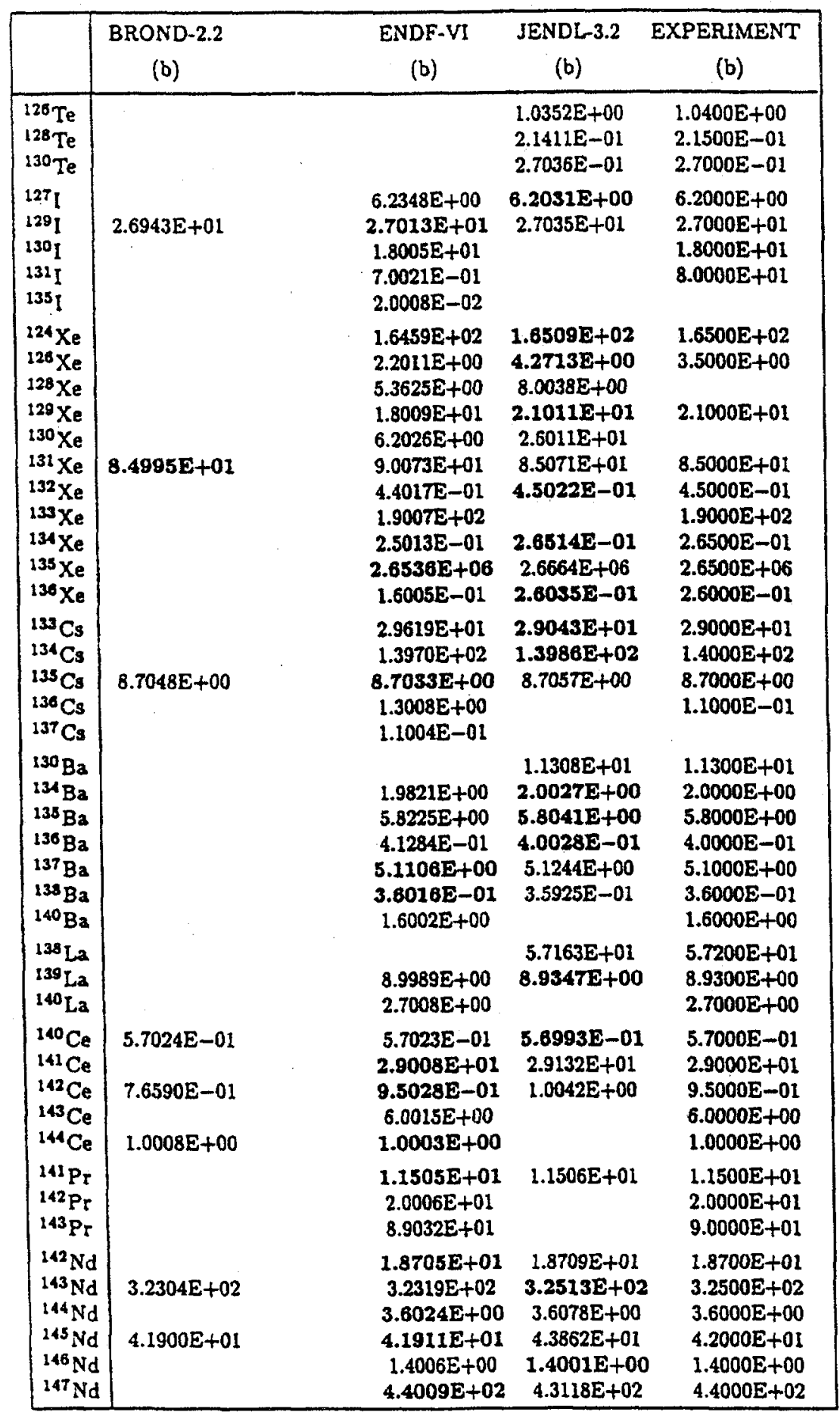


Table 8. (Contd.)

Capture cross section at $\mathbf{0 . 0 2 5 3}$

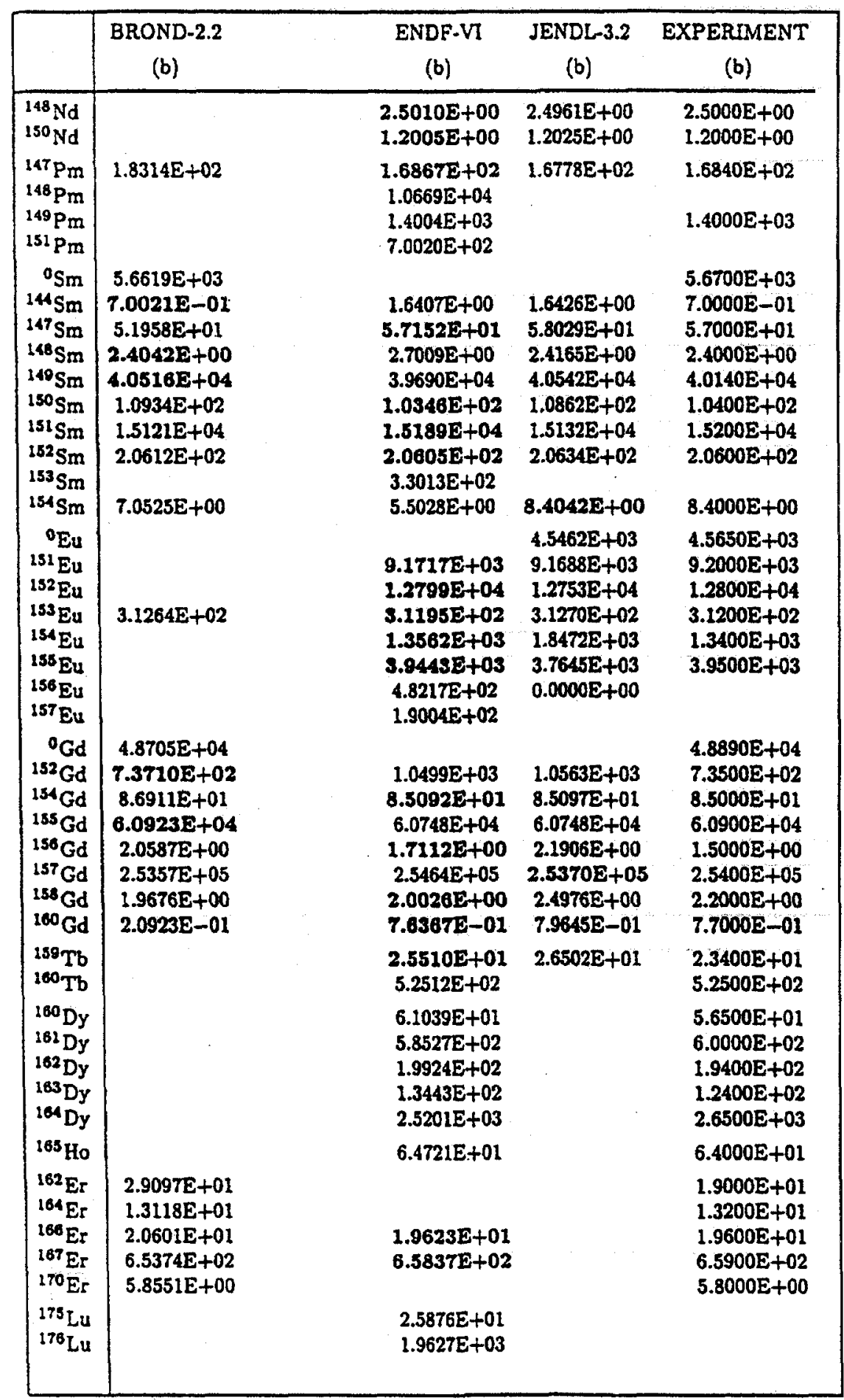


Table 9. Experimental Data Files For Sm Capture

\begin{tabular}{|c|c|c|c|c|c|}
\hline Nuclide & $\mathrm{Lab}$ & Author-year & EMIN & EMAX & \# PTS \\
\hline 144-Sm & ORNL, USA & Macklin-93 & $6.0+3$ & $5.0+5$ & 15 \\
\hline 144-Sm & ORNL, USA & Alexander-87 & $2.53-2$ & & 1 \\
\hline 144-Sm & FEI, RUS & Kononov-77 & $7.5+3$ & $3.4+5$ & 30 \\
\hline $145-\mathrm{Sm}$ & ORNL, USA & Alexander-87 & $2.53-2$ & & 1 \\
\hline 147-Sm & ORNL, USA & Macklin-86 & $3.0+3$ & $7.0+5$ & 18 \\
\hline 147-Sm & $\mathrm{SAC}, \mathrm{FR}$ & Lucas-77 & $2.53-2$ & & 1 \\
\hline $147-\mathrm{Sm}$ & FEI, RUS & Kononov-77 & $5.5+3$ & $3.4+5$ & 75 \\
\hline 147-Sm & FEI, RUS & Bokhovko-85 & $5.0+3$ & $4.0+5$ & 57 \\
\hline $147-\mathrm{Sm}$ & KFK, GER & Wisshak-93 & $3.0+3$ & $2.25+5$ & 18 \\
\hline 148-Sm & FEI, RUS & Kononov-77 & $5.5+3$ & $1.9+5$ & 75 \\
\hline $148-\mathrm{Sm}$ & KFK, GER & Wisshak-93 & $3.0+3$ & $2.25+5$ & 18 \\
\hline 149-Sm & ORNL, USA & Macklin-86 & $3.0+3$ & $7.0+5$ & 18 \\
\hline 149-Sm & FEI, RUS & Kononov-77 & $5.5+3$ & $3.4+5$ & 75 \\
\hline 149-Sm & KFK, GER & Wisshak-93 & $3.0+3$ & $2.25+5$ & 18 \\
\hline $150-\mathrm{Sm}$ & FEI, RUS & Kononov-77 & $5.0+3$ & $2.0+5$ & 33 \\
\hline $150-\mathrm{Sm}$ & KFK, GER & Wisshak-93 & $3.0+3$ & $2.25+5$ & 18 \\
\hline $152-\mathrm{Sm}$ & AEP, CPR & Zhou Zu-ying & $1.59+5$ & $1.47+6$ & 6 \\
\hline $152-\mathrm{Sm}$ & SIU, CPR & Luo Xiao-bing & $2.2+4$ & $1.0+6$ & 10 \\
\hline $152-\mathrm{Sm}$ & FEI, RUS & Kononov-77 & $5.0+3$ & $3.5+5$ & 38 \\
\hline $152-\mathrm{Sm}$ & $\mathrm{RI}, \mathrm{CCP}$ & Trofimov-87 & $2.0+6$ & & 1 \\
\hline $152-\mathrm{Sm}$ & $\mathrm{RI}, \mathrm{CCP}$ & Trofimov- 87 & $1.0+6$ & & 1 \\
\hline $152-\mathrm{Sm}$ & FEI, RUS & Bokhovko-85 & $5.0+3$ & $4.0+5$ & 57 \\
\hline $152-\mathrm{Sm}$ & KFK, GER & Wisshak-93 & $3.0+3$ & $2.25+5$ & 18 \\
\hline $154-\mathrm{Sm}$ & JYV, SF & Valkonen-76 & $1.4+7$ & & 1 \\
\hline $154-\mathrm{Sm}$ & MUA, IND & Ansari-78 & $4.7+5$ & $6.8+5$ & 2 \\
\hline 154-Sm & PUC, IND & Ansari-86 & $1.1+6$ & $2.0+6$ & 5 \\
\hline 154-Sm & FEI, RUS & Kononov-77 & $5.0+3$ & $3.5+5$ & 38 \\
\hline 154-Sm & RI, CCP & Trofimov-87 & $2.0+6$ & & 1 \\
\hline 154-Sm & $\mathrm{RI}, \mathrm{CCP}$ & Trofimov- 87 & $1.0+6$ & & 1 \\
\hline
\end{tabular}


Table 10. Fission Product Evaluations

\begin{tabular}{|c|c|c|c|c|c|}
\hline \multicolumn{4}{|c|}{ ENDF/B-VI } & \multicolumn{2}{|c|}{ REVISED } \\
\hline Nuclide & mat/tape & EHIR & $\mathrm{RF}, \mathrm{NR}, \mathrm{UN}$ & EHIR & $\mathrm{RF}, \mathrm{NR}, \mathrm{UN}$ \\
\hline Cs-134 & $5528 / 103$ & 180 & $\mathrm{ML}, 7$ & 180 & $\mathrm{ML}, 8, \mathrm{UN}$ \\
\hline Cs-135 & $5531 / 105$ & \multicolumn{2}{|c|}{ RP NOT GIVEN } & 210 & $\mathrm{ML}, 7, \mathrm{UN}$ \\
\hline $\mathrm{BA}-134$ & $5637 / 103$ & 2072 & ML, 9 & 10000 & $\mathrm{RM}, 87, \mathrm{UN}$ \\
\hline SM-149 & $6240 / 106$ & 100 & $\mathrm{ML}, 30, \mathrm{UN}$ & 500 & ML, $158, \mathrm{UN}$ \\
\hline EU-154 & $6334 / 103$ & 63 & ML,59,UN & 63 & $\mathrm{ML}, 60, \mathrm{UN}$ \\
\hline EU-155 & $6337 / 120$ & 35 & $\mathrm{ML}, 7$ & 37.5 & $\mathrm{ML}, 8, \mathrm{UN}$ \\
\hline DY-160 & $6637 / 106$ & 24.44 & $\mathrm{SL}, 3$ & 1690 & ML,66,UN \\
\hline DY-161 & $6640 / 106$ & 67.64 & SL, 27 & 1000 & $\mathrm{ML}, 254, \mathrm{UN}$ \\
\hline DY-162 & $6643 / 106$ & 430.2 & SL, 8 & 12200 & $\mathrm{ML}, 142, \mathrm{UN}$ \\
\hline DY -163 & $6646 / 106$ & 487.6 & SL, 60 & 1000 & $\mathrm{ML}, 115$ \\
\hline DY-164 & $6649 / 106$ & 272.0 & SL, 2,UN & 16000 & $\mathrm{ML}, 117, \mathrm{UN}$ \\
\hline LU-175 & $7125 / 106$ & 60.0 & SL, $17, \mathrm{UN}$ & 411 & ML, $115, \mathrm{UN}$ \\
\hline LU-176 & $7128 / 106$ & 48.0 & SL,21,UN & 102 & $\mathrm{ML}, 59, \mathrm{UN}$ \\
\hline $\begin{array}{l}\mathrm{EHIR}= \\
\mathrm{RF}= \\
\mathrm{NR}= \\
\mathrm{UN}=\end{array}$ & $\begin{aligned}= & \text { upper limit of resc } \\
& \text { resolved resonanc } \\
& \mathrm{ML}=\text { Reich-Moo } \\
& \mathrm{SL}=\text { Mingli-level } \\
= & \text { number of resolve } \\
= & \text { unresolved resona }\end{aligned}$ & $\begin{array}{l}\text { age }(\mathrm{eV}) \\
\text { lism } \\
\text { igner } \\
\text { igner } \\
\text { ances } \\
\text { given } \\
\end{array}$ & & & \\
\hline
\end{tabular}


Table 11. Fission Product Evaluations Number of Points

\begin{tabular}{|l|l|l|l||}
\hline \multicolumn{3}{|c|}{ REVISED EVALUATION } \\
\hline \hline Nuclide & EHIR & RF,NR,UN & NUMBER OF POINTS \\
\hline Cs-134 & 180 & ML, 8, UN & 2293 \\
\hline Cs-135 & 210 & ML, 7, UN & 2058 \\
\hline Ba-134 & 10000 & RM,87,UN & 9853 \\
\hline Sm-149 & 500 & ML,158,UN & 17942 \\
\hline Eu-154 & 63 & ML,60,UN & 4592 \\
\hline Eu-155 & 37.5 & ML,8,UN & 1525 \\
\hline Dy-160 & 1690 & ML,66,UN & 14341 \\
\hline Dy-161 & 1000 & ML,254,UN & 35579 \\
\hline Dy-162 & 12200 & ML,142,UN & 26447 \\
\hline Dy-163 & 1000 & ML,115 & 22550 \\
\hline Dy-164 & 16000 & ML,117,UN & 19532 \\
\hline Lu-175 & 411 & ML,115,UN & 17993 \\
\hline Lu-176 & 102 & ML,59,UN & 8534 \\
\hline $\begin{array}{l}\text { EHIR }=\begin{array}{l}\text { upper limit of resolved range (eV) } \\
\text { RF } \\
\text { resolved resonance formalism }=\text { Reich-Moore } \\
\text { SL }=\text { Multi-level Breit-Wigner }\end{array} \\
\text { number of resolved resonances } \\
\text { unresolved resonance data given }\end{array}$ \\
\hline NJOY tolerance $=0.001$ & & \\
\hline
\end{tabular}


Table 12. Unresolved Resonance Parameters

(Compiled 4-27-98)

\begin{tabular}{|c|c|c|c|c|c|c|}
\hline NUCLIDE & So & $\mathrm{Sl}$ & $\mathrm{D} 0$ & $\mathrm{GG}$ & GG/D0 & $\mathrm{R}$ \\
\hline Cs-134 & 1.4 & 1.3 & 5.78 & 0.160 & 276.7 & 5.30 \\
\hline Cs-135 & 1.4 & 1.2 & 115 & 0.160 & 14.0 & 5.30 \\
\hline $\mathrm{Ba}-134$ & 1.2 & 3.2 & 294 & 0.0778 & 2.65 & 5.14 \\
\hline Sm-149 & 4.4 & 0.4 & 1.72 & 0.062 & 360.7 & 8.30 \\
\hline Eu-154 & 2.57 & 0.61 & 0.975 & 0.126 & 1292 & 8.80 \\
\hline Eu-155 & 2.3 & 0.5 & 4.19 & 0.094 & 224.5 & 7.40 \\
\hline Dy-160 & 1.8 & 1.0 & 30 & 0.108 & 36.0 & 7.50 \\
\hline Dy-161 & 1.9 & 1.0 & 1.98 & 0.113 & 570.7 & 7.50 \\
\hline Dy-162 & 1.8 & 1.1 & 65 & 0.112 & 17.23 & 7.82 \\
\hline Dy-163 & \multicolumn{6}{|c|}{ unresolved parameters not given } \\
\hline Dy-164 & 1.7 & 1.3 & 188 & 0.114 & 6.0683 & 7.82 \\
\hline Lu-175 & 1.7 & 1.4 & 3.27 & 0.077 & 235.6 & 7.70 \\
\hline Lu-176 & 1.6 & 1.4 & 2.69 & 0.090 & 334.4 & 7.60 \\
\hline \multicolumn{7}{|c|}{$\begin{array}{l}\text { S0 = s-wave strength function (units of } 1.0-4) \\
\text { S1 = p-wave strength function (units of } 1.0-4) \\
\text { D0 = s-wave level spacing (eV) } \\
\text { GG = GAMMA-GAMMA }(\mathrm{eV}) \\
\text { GG/D0 = s-wave gamma-ray strength function } \\
\text { (units of } 1.0-4 \text { ) } \\
\mathrm{R}=\text { scattering radius (fm) }\end{array}$} \\
\hline
\end{tabular}


Table 13. Thermal Capture Cross Sections and Resonance Integrals

\begin{tabular}{||r|r|r|r|r|r||}
\hline \multicolumn{3}{|c|}{ ENDF/B-VI } & \multicolumn{2}{c|}{ Revised } \\
\hline \hline Nuclide & Mat/tape & Capture & R.I. & Capture & R.I. \\
\hline \hline Cs-134 & $5528 / 103$ & 140 & 78 & 140 & 102 \\
\hline Cs-135 & $5531 / 105$ & 8.70 & 65 & 8.45 & 50 \\
\hline Ba-134 & $5637 / 103$ & 1.98 & 24 & 1.40 & 22 \\
\hline Sm-149 & $6240 / 106$ & 39698 & 3264 & 40425 & 3426 \\
\hline Eu-154 & $6334 / 103$ & 1357 & 1345 & 1846 & 1357 \\
\hline Eu-155 & $6337 / 120$ & 3944 & 23445 & 3760 & 15288 \\
\hline Dy-160 & $6637 / 106$ & 61 & 1674 & 57 & 1105 \\
\hline Dy-161 & $6640 / 106$ & 585 & 1215 & 600 & 1085 \\
\hline Dy-162 & $6643 / 106$ & 199 & 2778 & 194 & 2745 \\
\hline Dy-163 & $6646 / 106$ & 134 & 1465 & 124 & 1487 \\
\hline Dy-164 & $6649 / 106$ & 2520 & 329 & 2650 & 342 \\
\hline Lu-175 & $7125 / 106$ & 26 & 642 & 23 & 622 \\
\hline Lu-176 & $7128 / 106$ & 1953 & 918 & 2098 & 922 \\
\hline $\begin{array}{l}\text { CAPTURE = thermal capture at } 2200 \mathrm{~m} / \mathrm{s} \text { (barns) } \\
\text { R.I. = capture resonance integral (barns) }\end{array}$ \\
\hline
\end{tabular}


Table 14. Maxwellian Averaged Capture Cross sections for $30 \mathrm{keV}(\mathrm{mb})$

\begin{tabular}{|c|c|c|c|c|c|}
\hline Nuclide & Mat & ENDF/B-VI & Revised & Measured & Reference \\
\hline Cs-134 & 5528 & 588 & 1118 & $(958)$ & 11 \\
\hline Cs-135 & 5531 & 67 & 203 & (201) & 11 \\
\hline $\mathrm{Ba}-134$ & 5637 & 120 & 178 & 179 & 12 \\
\hline $\mathrm{Sm}-149$ & 6240 & 2391 & 1808 & 1820 & 19 \\
\hline Eu-154 & 6334 & 3079 & 3080 & $(3720)$ & 11 \\
\hline Eu-155 & 6337 & 2255 & 1337 & 1320 & 20 \\
\hline Dy-160 & 6637 & 1570 & 712 & 699 & 16 \\
\hline Dy-161 & 6640 & 198.4 & 1928 & 1936 & 16 \\
\hline Dy-162 & 6643 & 719 & 408 & 476 & 17 \\
\hline Dy-163 & 6646 & 827 & 1116 & 1153 & 16 \\
\hline Dy-164 & 6649 & 244 & 204 & 268 & 17 \\
\hline Lu-175 & 7125 & 1375 & 1320 & 1206 & 18 \\
\hline $\mathrm{Lu}-176$ & 7128 & 2115 & 1545 & 1526 & 16 \\
\hline
\end{tabular}


Table 15. One-Group Average Fission-Product Cross Sections (b)

Fast Reactor Weight Function

\begin{tabular}{|c|c|c|c|c|}
\hline Nuclide & Total & Elastic & Inelastic & Capture \\
\hline Cs-134 & 7.316 & 5.402 & 0.7541 & 1.1600 \\
\hline Cs-135 & 7.366 & 6.888 & 0.2508 & 0.2272 \\
\hline Ba-134 & 7.238 & 6.915 & 0.1686 & 0.1547 \\
\hline Sm-149 & 14.61 & 11.12 & 1.2090 & 2.2700 \\
\hline Eu-154 & 11.90 & 7.918 & 0.8895 & 3.0900 \\
\hline Eu-155 & 11.21 & 8.815 & 0.8875 & 1.5070 \\
\hline Dy-160 & 10.71 & 9.620 & 0.3431 & 0.7471 \\
\hline Dy-161 & 10.73 & 8.092 & 0.7881 & 1.8470 \\
\hline Dy-162 & 10.98 & 10.08 & 0.4501 & 0.4490 \\
\hline Dy-163 & 10.81 & 8.899 & 0.7852 & 1.1300 \\
\hline Dy-164 & 10.13 & 8.948 & 0.9583 & 0.2194 \\
\hline Lu-175 & 10.81 & 8.656 & 0.7849 & 1.3680 \\
\hline Lu-176 & 10.57 & 8.173 & 0.7883 & 1.6070 \\
\hline
\end{tabular}


Table 16. One-Group Average Fission-Product Cross Sections (b)

Fast Reactor Weight Function

\begin{tabular}{|c|c|c|c|c|}
\hline Nuclide & Total & Elastic & Inelastic & Capture \\
\hline Mo-95 & 7.864 & 7.276 & 0.2637 & 0.3244 \\
\hline Tc-99 & 9.126 & 8.050 & 0.4177 & 0.6580 \\
\hline Ru-101 & 7.780 & 6.518 & 0.5061 & 0.7557 \\
\hline Rh-103 & 8.321 & 7.105 & 0.4832 & 0.7325 \\
\hline Ag-109 & 8.335 & 7.260 & 0.4413 & 0.6336 \\
\hline Xe-131 & 7.878 & 7.104 & 0.4944 & 0.2781 \\
\hline Cs-133 & 8.010 & 6.960 & 0.5245 & 0.5251 \\
\hline Nd-143 & 11.26 & 10.75 & 0.1453 & 0.3606 \\
\hline Nd-145 & 12.17 & 11.15 & 0.5012 & 0.5222 \\
\hline Sm-147 & 15.01 & 13.28 & 0.4797 & 1.2460 \\
\hline Sm-150 & 12.26 & 11.40 & 0.4286 & 0.4297 \\
\hline Sm-151 & 12.56 & 7.382 & 2.2310 & 2.9430 \\
\hline Sm-152 & 11.22 & 10.12 & 0.6087 & 0.4856 \\
\hline Eu-151 & 13.39 & 8.511 & 0.8924 & 3.9870 \\
\hline Eu-153 & 10.78 & 7.247 & 0.9746 & 2.5550 \\
\hline Gd-155 & 11.41 & 7.167 & 1.3320 & 2.9050 \\
\hline
\end{tabular}


Table 17. One-Group Average Fission-Product Capture Cross Sections (b) Fast Reactor Weight Function

\begin{tabular}{|c|c|c|c|}
\hline Nuclide & JEF-2.2 & JENDL-3.2 & ENDF/B-VI \\
\hline Cs-134 & & & 1.1600 \\
\hline Cs-135 & 0.2379 & 0.2284 & 0.2272 \\
\hline Ba-134 & 0.1164 & 0.2081 & 0.1547 \\
\hline Sm-149 & 2.5398 & 2.2990 & 2.2700 \\
\hline Eu-154 & 3.0951 & 3.4503 & 3.0900 \\
\hline Eu-155 & 2.8163 & 1.3368 & 1.5070 \\
\hline Dy-160 & 2.2301 & & 0.7471 \\
\hline Dy-161 & 2.5911 & & 1.8470 \\
\hline Dy-162 & 0.9439 & & 0.4490 \\
\hline Dy-163 & & & 1.1300 \\
\hline Dy-164 & & & 0.2194 \\
\hline Lu-175 & & & 1.3680 \\
\hline Lu-176 & & & 1.6070 \\
\hline
\end{tabular}


Table 18. One-Group Average Fission-Product Capture Cross Sections (b) Fast Reactor Weight Function

\begin{tabular}{|c|c|c|c|}
\hline Nuclide & JEF-2.2 & JENDL-3.2 & ENDF/B-VI \\
\hline \hline Mo-95 & 0.3180 & 0.3360 & 0.3244 \\
\hline Tc-99 & 0.6301 & 0.5923 & 0.6580 \\
\hline Ru-101 & 0.7143 & 0.7523 & 0.7557 \\
\hline Rh-103 & 0.6751 & 0.6774 & 0.7325 \\
\hline Ag-109 & 0.7846 & 0.6916 & 0.6336 \\
\hline Xe-131 & 0.2917 & 0.3461 & 0.2781 \\
\hline Cs-133 & 0.5072 & 0.4874 & 0.5251 \\
\hline Nd-143 & 0.3592 & 0.3589 & 0.3606 \\
\hline Nd-145 & 0.5657 & 0.5648 & 0.5222 \\
\hline Sm-147 & 1.4571 & 1.2719 & 1.2460 \\
\hline Sm-150 & 0.4543 & 0.4341 & 0.4297 \\
\hline Sm-151 & 3.3618 & 2.1080 & 2.9430 \\
\hline Sm-152 & 0.4951 & 0.4799 & 0.4856 \\
\hline Eu-151 & & & 3.9870 \\
\hline Eu-153 & 2.7363 & 2.5958 & 2.5550 \\
\hline Gd-155 & 2.9068 & 2.6347 & 2.9050 \\
\hline
\end{tabular}


Table 19. Summary of Recommendations

\section{Section 2.0}

Resolved resonance parameters should be included for a larger number of ENDF/B-VI evaluations, e.g. ${ }^{93} \mathrm{Zr},{ }^{110} \mathrm{Pd},{ }^{136} \mathrm{Xe},{ }^{135} \mathrm{Cs},{ }^{140} \mathrm{Ce},{ }^{142} \mathrm{Ce}$, and ${ }^{148} \mathrm{Sm}$. Unresolved resonance parameters should be included for new or revised ENDF/B-VI evaluations. The ENDF/B-VI ${ }^{99} \mathrm{Tc}$ unresolved resonance parameters need to be revised.

The seven fission products given in Table 6 which were not revised for ENDF/B-VI should be reviewed again, taking into account the possible existence of experimental data that may have become available since 1980 .

An evaluation for ${ }^{169} \mathrm{Tm}$ needs to be added to ENDF/B-VI.

\section{Section 3.0}

A number of evaluations need improvement in the keV-MeV range. This can be accomplished by nuclear model calculations along with new experimental data that has become available since about 1975. Improved representation of the inelastic cross section is needed for a number of ENDF/B-VI evaluations.

\section{Section 4.0}

The 13 revised evaluations should be adopted for ENDF/B-VI.

\section{Section 5.0}

Comparisons of ENDF/B-VI fission-product evaluations with JEF-2.2, JENDL-3.2, and BROND-2 evaluations would be useful with particular emphasis on the fission-products that have the highest rank for fast reactor applications. New measurements of the capture cross sections and/or additional evaluation work would be desirable for both ${ }^{131} \mathrm{Xe}$ and ${ }^{15} \mathrm{Sm}$.

\section{Section 6.0}

Evaluations for ${ }^{162} \mathrm{Er},{ }^{164} \mathrm{Er},{ }^{168} \mathrm{Er}$, and ${ }^{170} \mathrm{Er}$ should be added to ENDF/B-VI. In addition, evaluations for ${ }^{170} \mathrm{Tm}$ and ${ }^{171} \mathrm{Tm}$ would be desirable. These evaluations are needed for applications using erbiumoxide as a burnable absorber. 
Table 20. Current Status and Recommendations for the Top 20 Fission-product Nuclides

Gd-155 Considered to be adequate for LWR spent-fuel applications but should be reviewed again.

Nd-143 Revised for ENDF/B-VI; considered to be adequate for LWR spent-fuel applications.

$\mathrm{Rh}-103$ Further review is recommended.

Sm-149 Revised evaluation described in this work recommended for ENDF/B-VI.

Sm-151 New measurements of the capture cross section and/or additional evaluation work would be desirable.

Cs-133 Further review is recommended.

$\mathrm{Xe}-131$ New measurements of the capture cross section and/or additional evaluation work is recommended.

Tc-99 Unresolved resonance parameters need to be revised and further review is recommended.

Sm-152 Revised for ENDF/B-VI; considered to be adequate for LWR spent-fuel applications.

Eu-153 New evaluation in ENDF/B-VI; considered to be adequate for LWR spent-fuel applications.

Nd-145 Revised for ENDF/B-VI; considered to be adequate for LWR spent-fuel applications.

Sm-147 Same as for Nd-145

$\mathrm{Sm}-150$ Same as for Nd-145

Ag-109 Further review is recommended.

Mo-95 Further review is recommended.

$\mathrm{Ru}-101$ Same as for Nd-145.

Eu-154 Revised evaluation described in this work recommended for ENDF/B-VI.

Cs-135 Same as for Eu-154.

Eu-155 Same as for Eu-154.

Eu-151 New evaluation in ENDF/B-VI; considered to be adequate for LWR spent-fuel applications. 


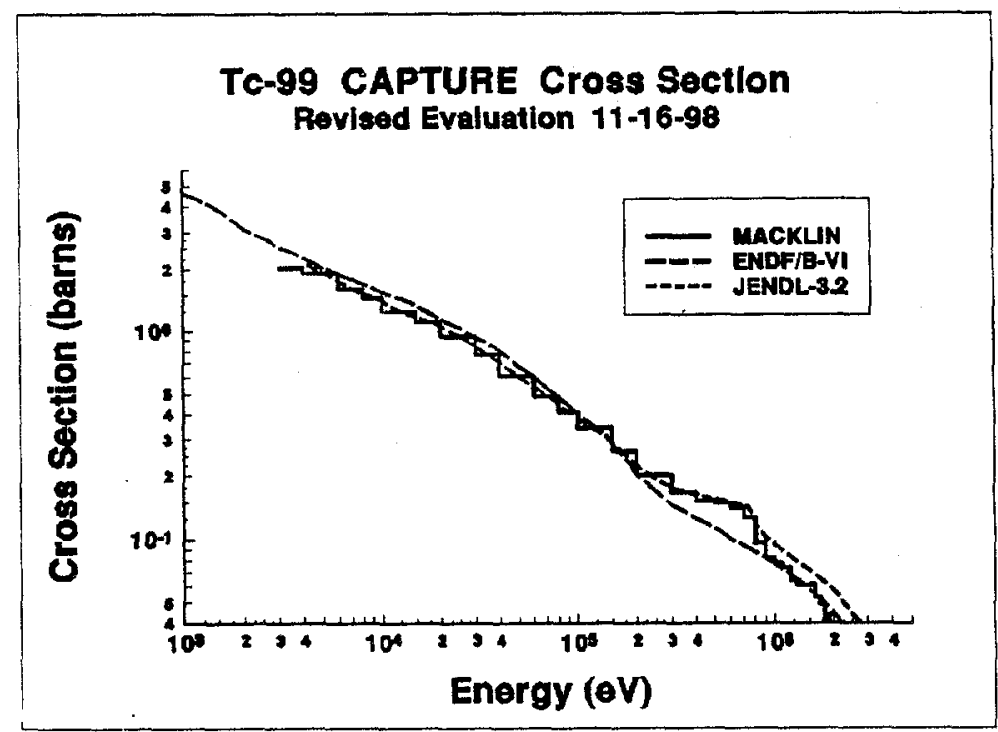

Fig. $1{ }^{99}$ Tc Capture cross section.

Fig. $2{ }^{113}$ In Capture cross section.
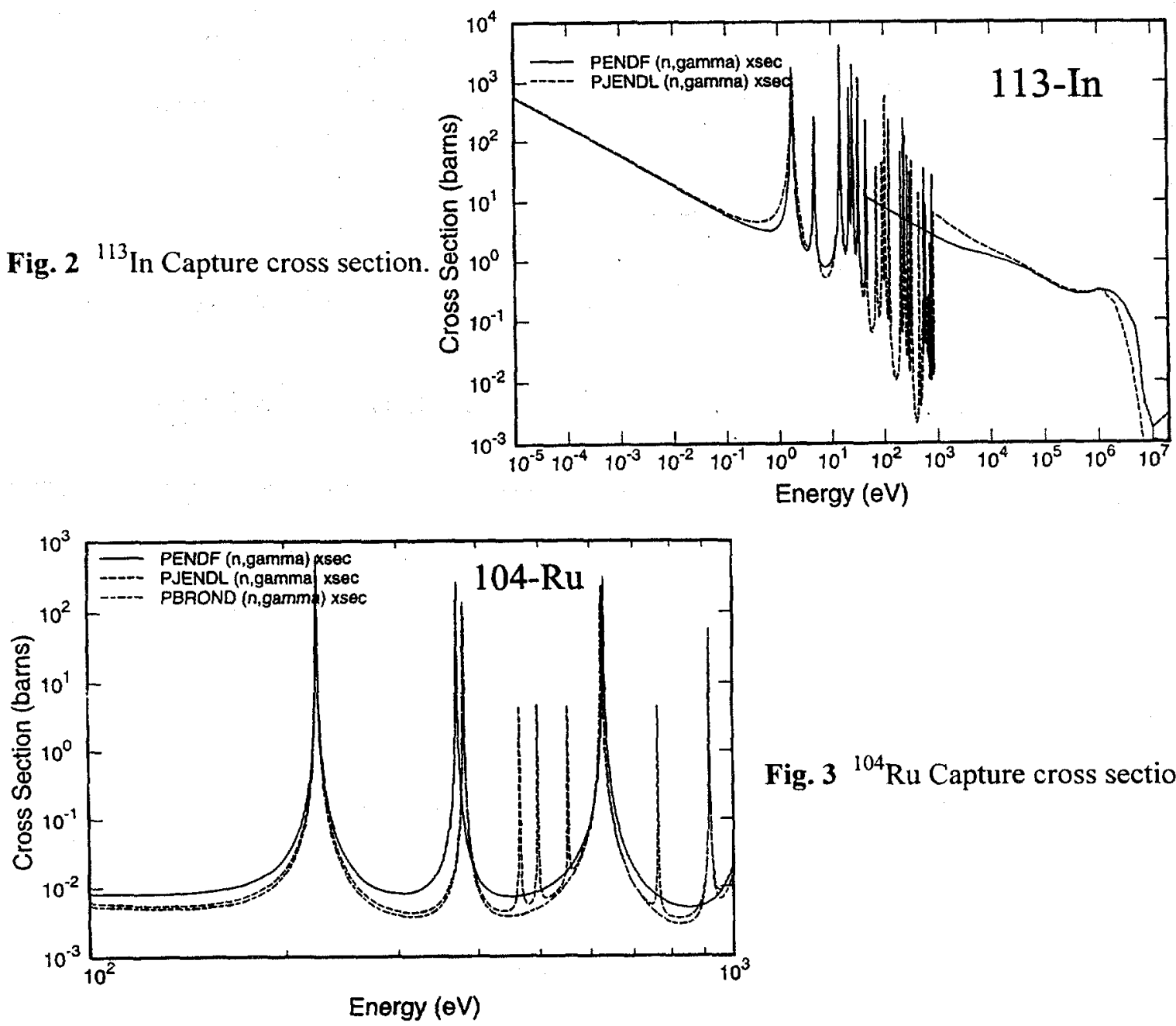

Fig. $3{ }^{104} \mathrm{Ru}$ Capture cross section. 

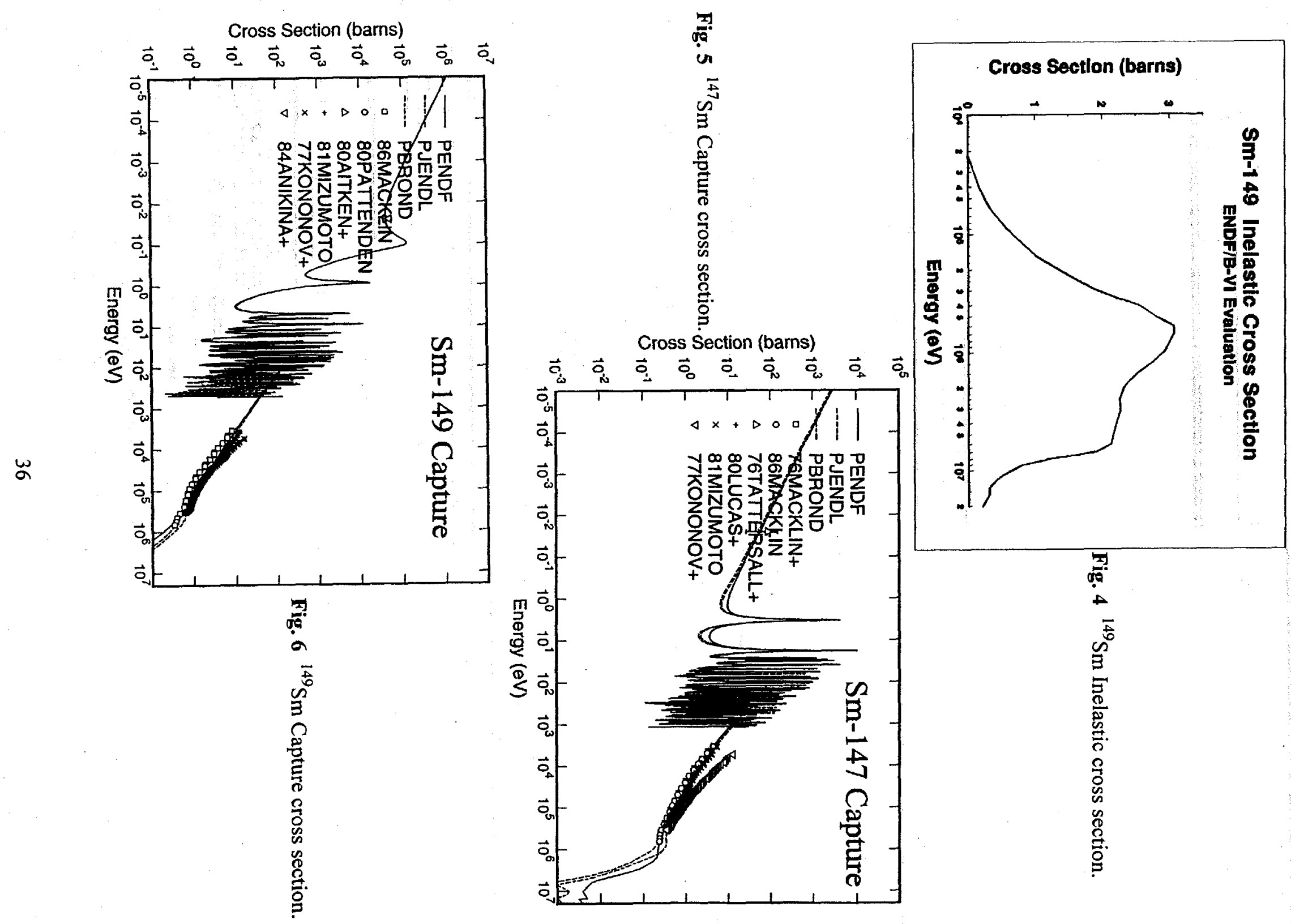

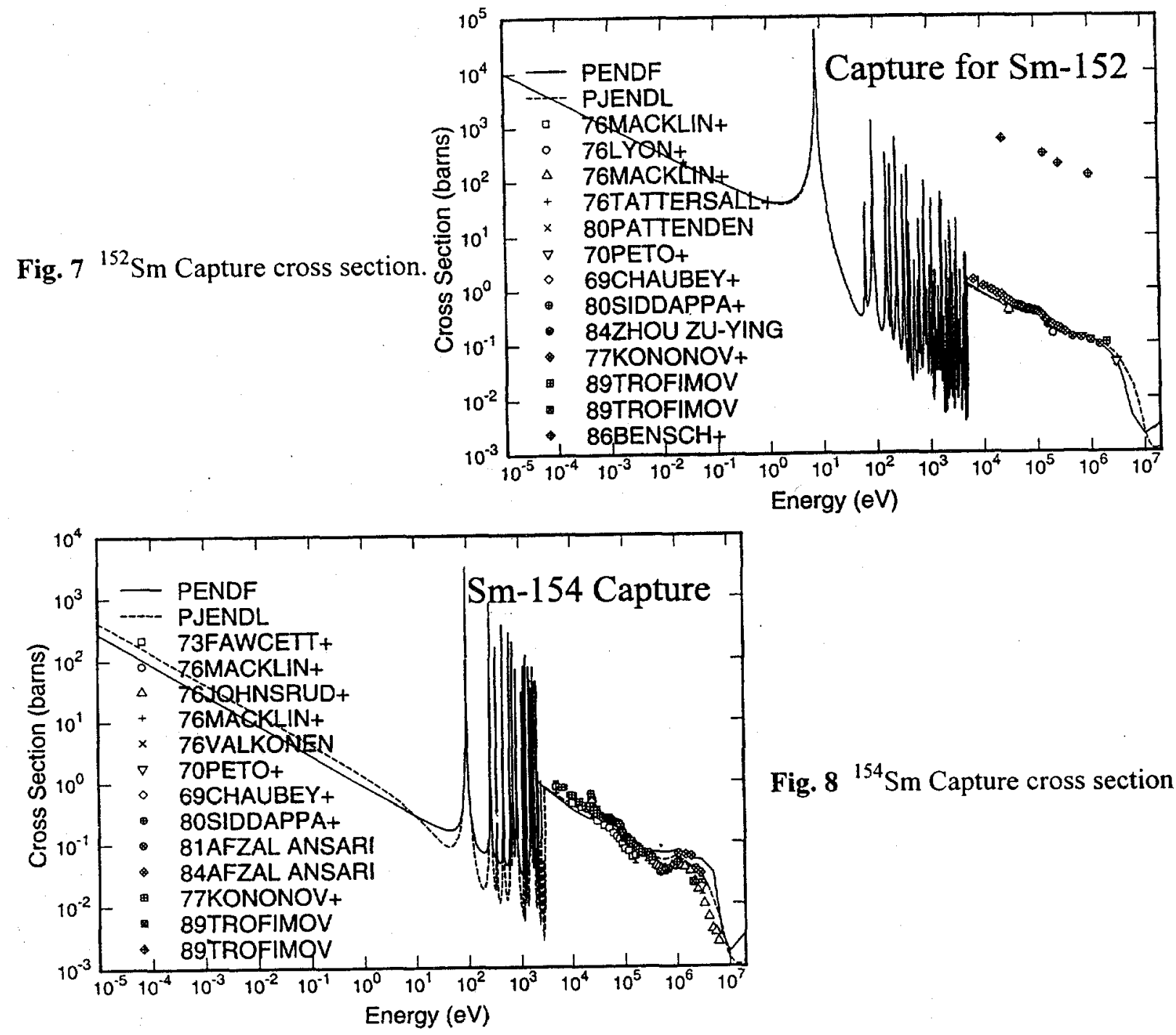

Fig. $8{ }^{154} \mathrm{Sm}$ Capture cross section.

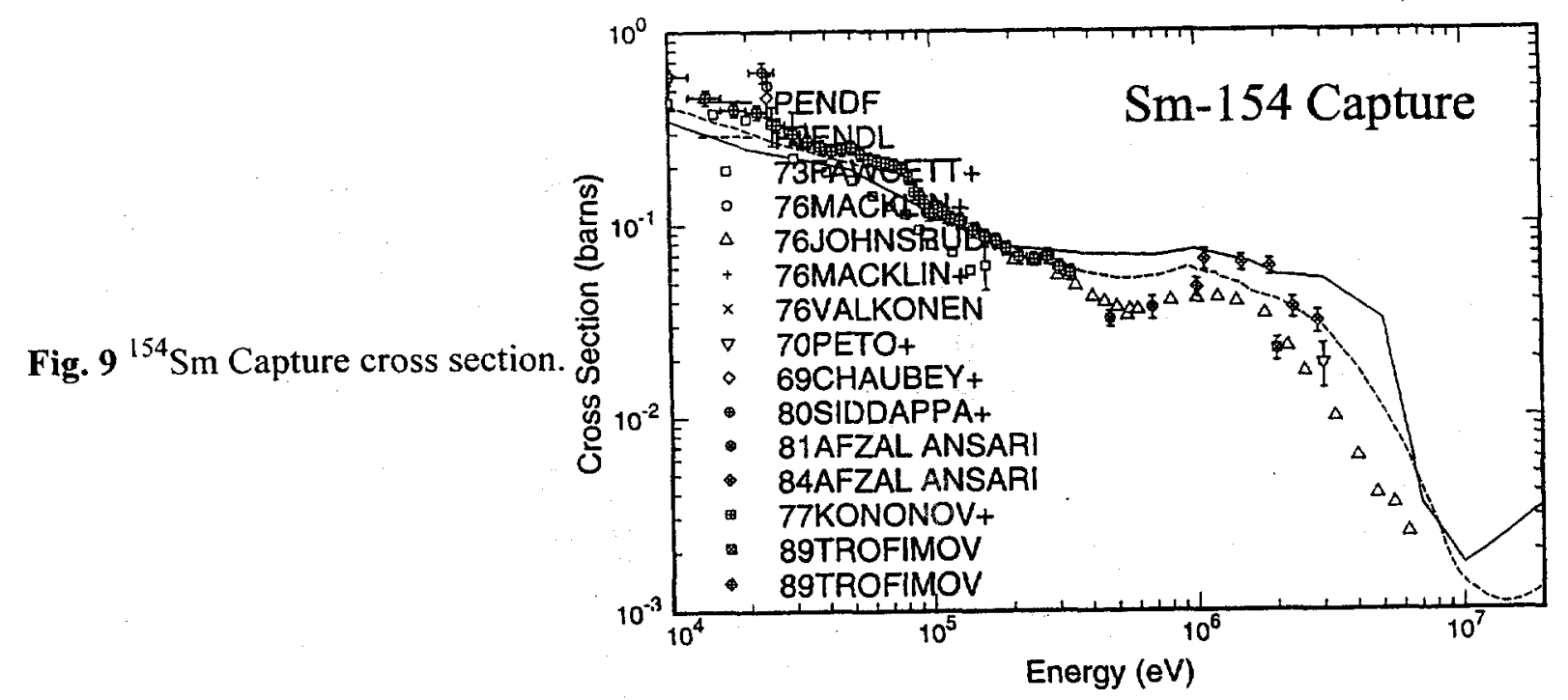




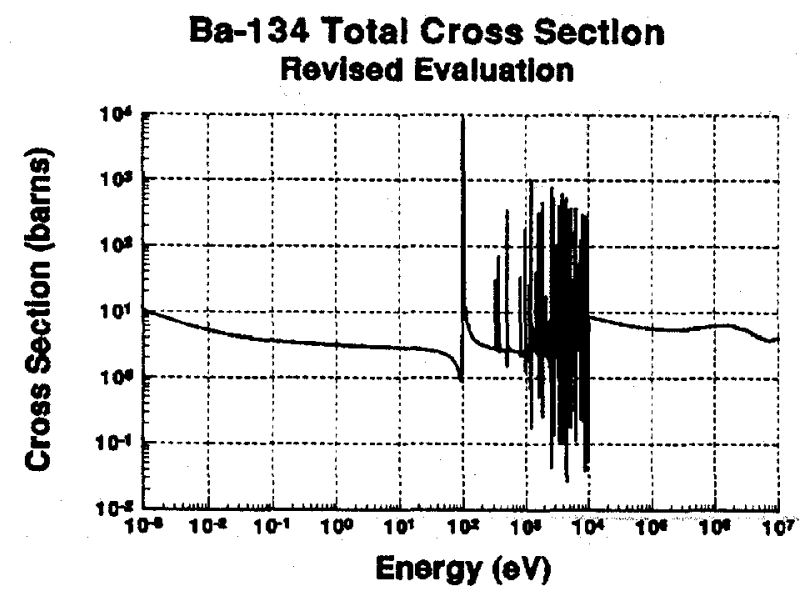

Fig. $10{ }^{134} \mathrm{Ba}$ Total cross section (revised).

Fig. $11^{149} \mathrm{Sm}$ Capture cross section (revised).

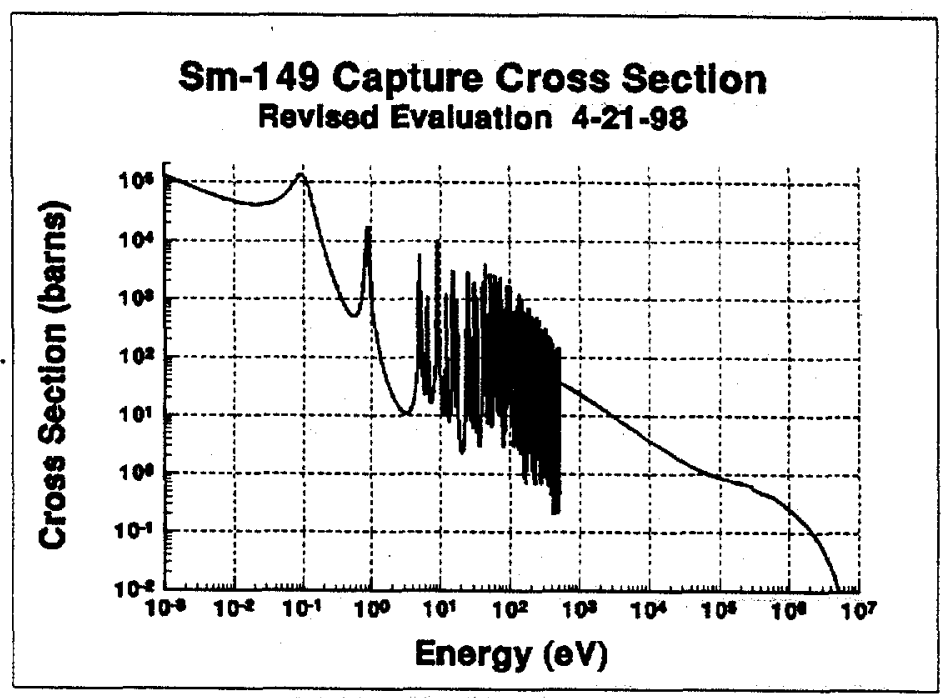

Eu-154 CAPTURE Cross-Section REVISED 12-12-97

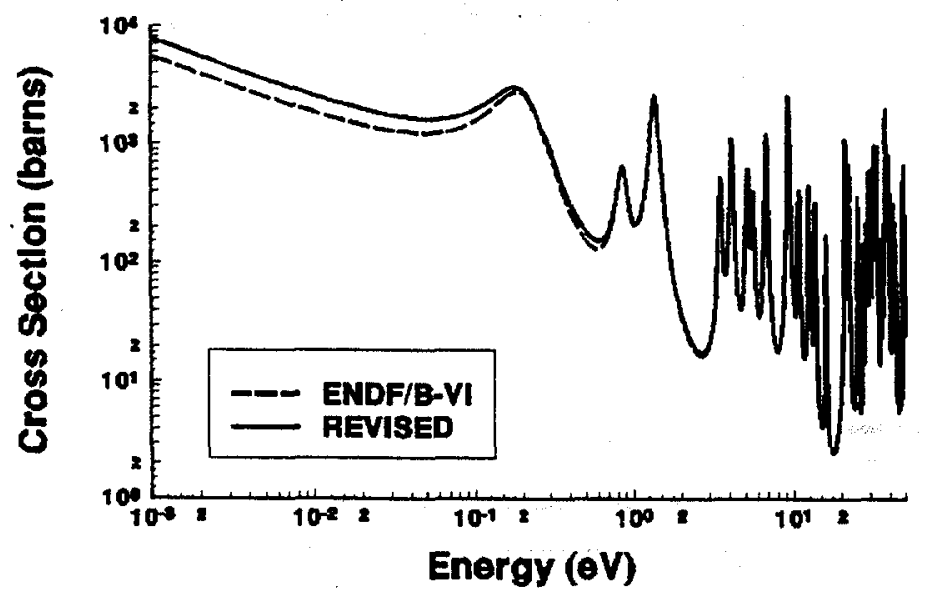

Fig. $12{ }^{154}$ Eu Capture cross sections (revised) 
Eu-155 CAPTURE Cross-Section

REVISED 12-12-97

Fig. $13{ }^{155}$ Eu Capture cross section (revised).

Dy-160 CAPTURE Cross-Section

REVISED $10-30-97$

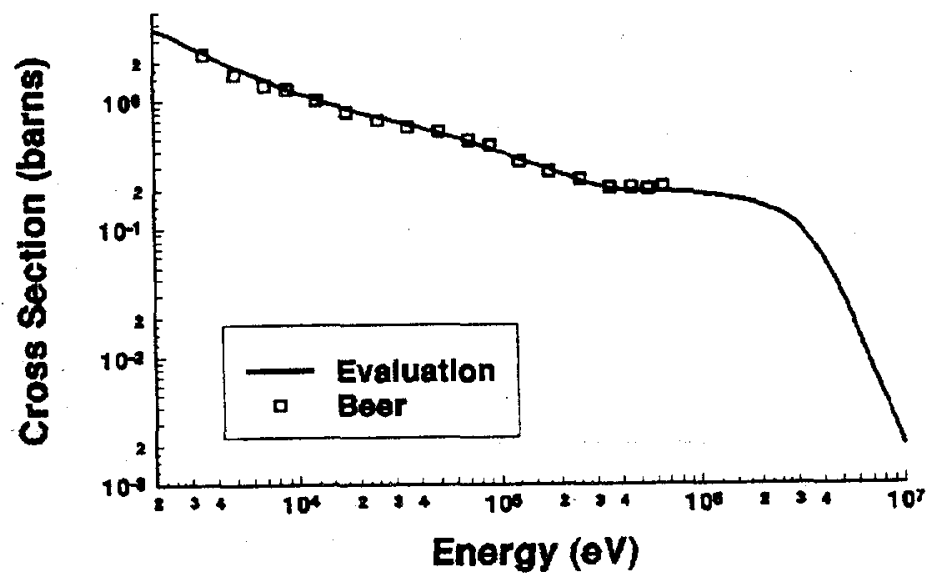

Dy-162 CAPTURE Cross-Section

REVISED 11-03-97

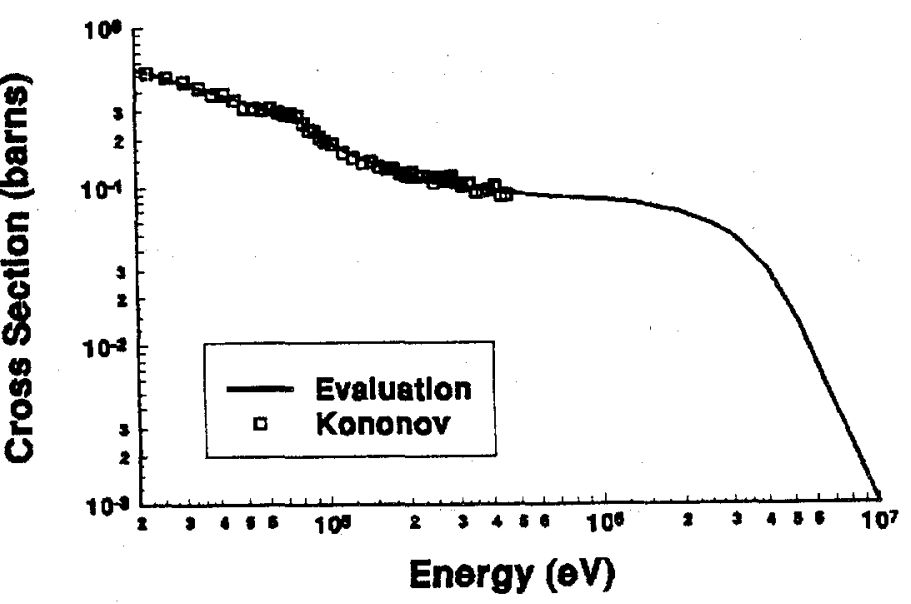


Dy-161 CAPTURE Cross-Section REVISED Evaluation 4-06-98

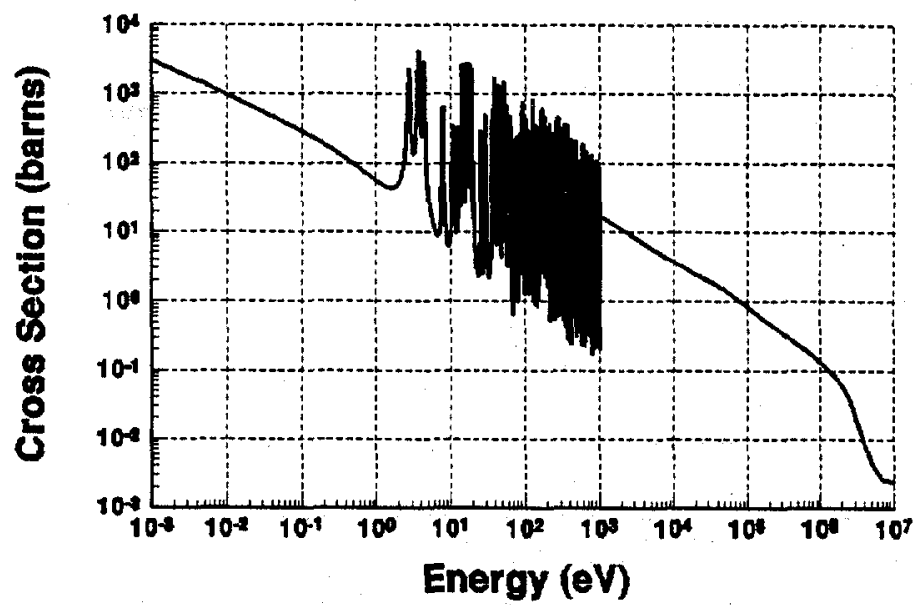

Fig. $16^{161}$ Dy Capture cross section (revised).

\section{Dy-164 CAPTURE Cross-Section} REVISED Evaluation 4-03-98

Fig. $17{ }^{164}$ Dy Capture cross section (revised)

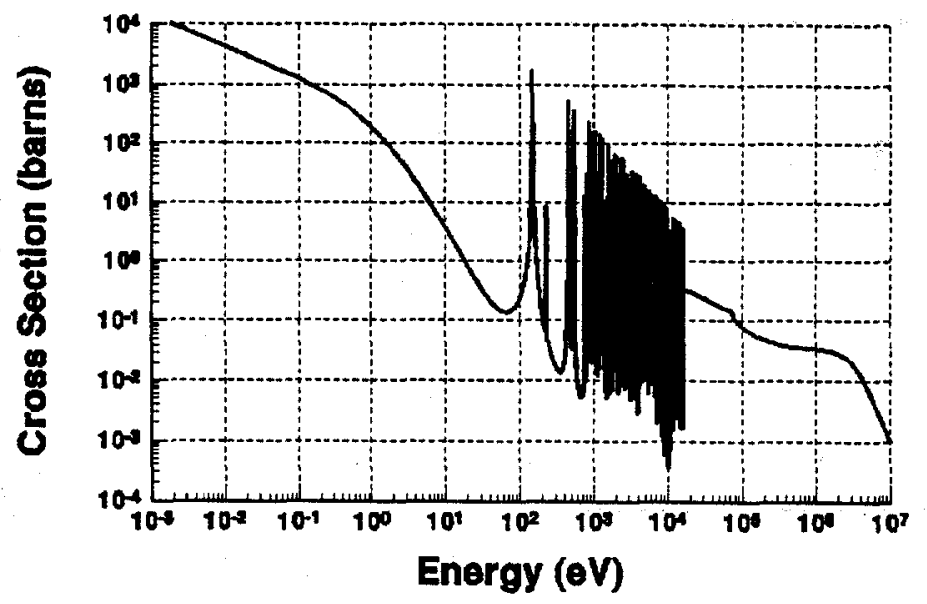

Dy-163 TOTAL Cross-Section REVISED Evaluation 4-08-98

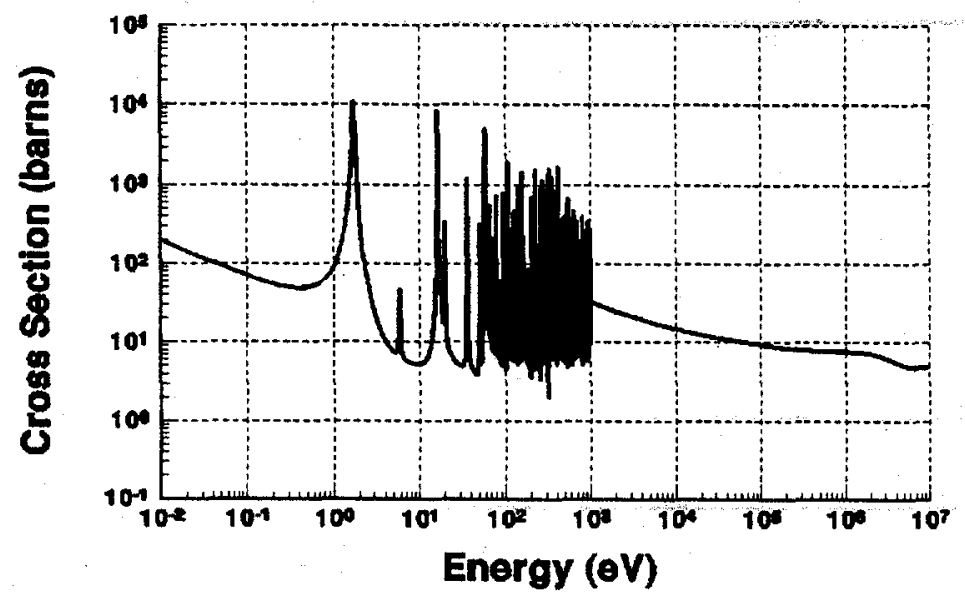

Fig. $18{ }^{163}$ Dy Total cross section (revised). 


\section{Lu-175 TOTAL Cross-Section}

REVISED 02-24-98

Fig. $19{ }^{175}$ Lu total cross section (revised).

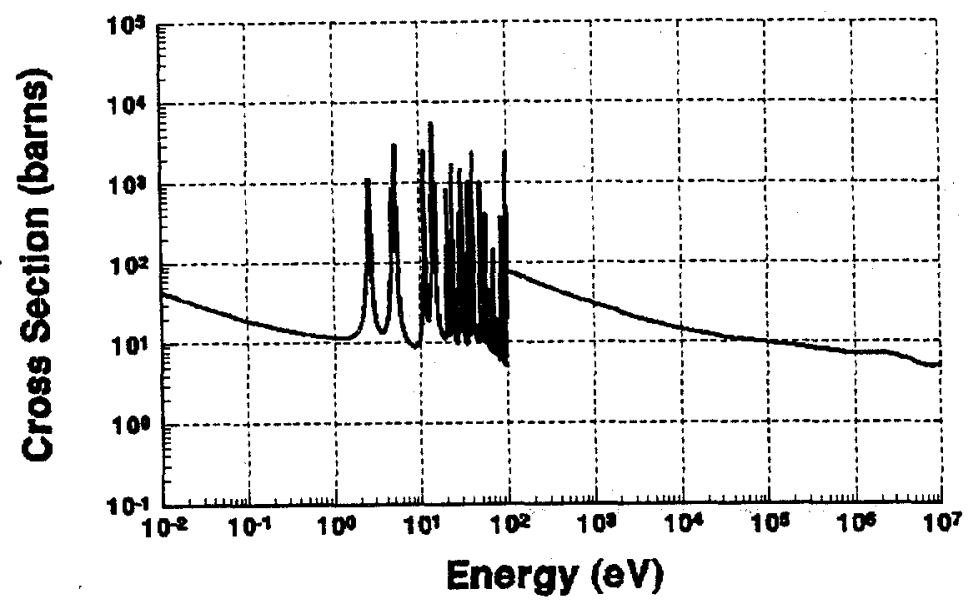

\section{Lu-176 CAPTURE Crose-Section} REVISED 01-22-98

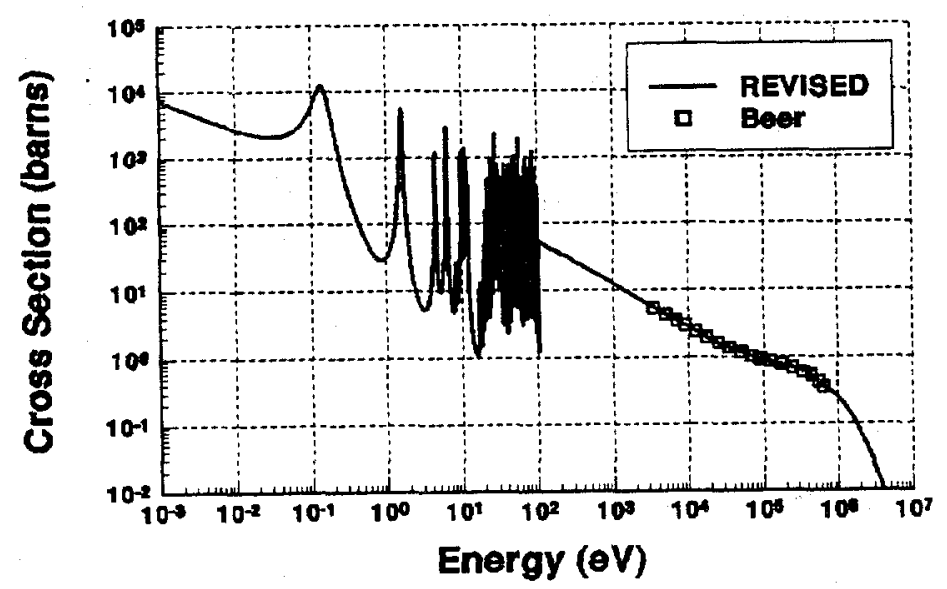

Fig. $20{ }^{176} \mathrm{Lu}$ Capture cross section (revised).

Cs-134 CAPTURE Cross Section Revised Evaluation 8-14-98

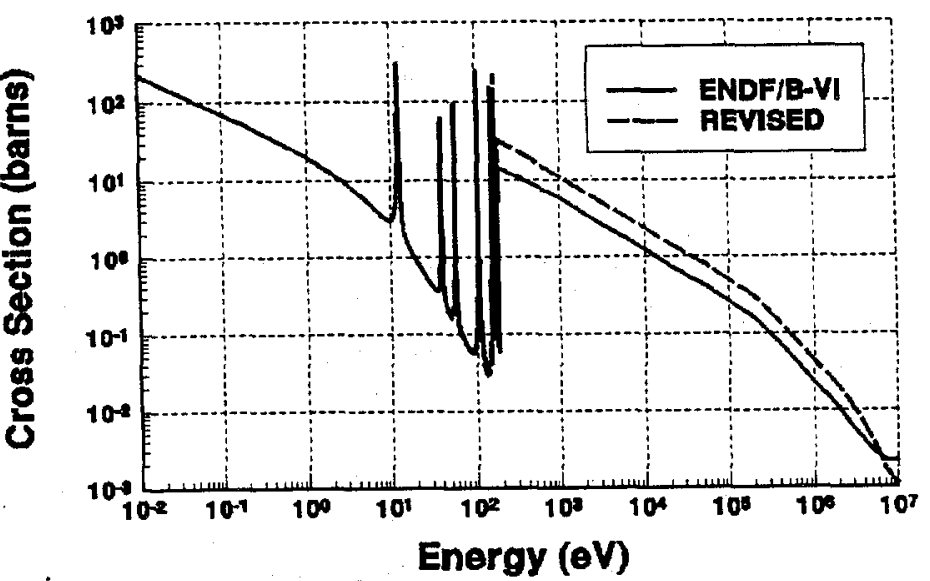




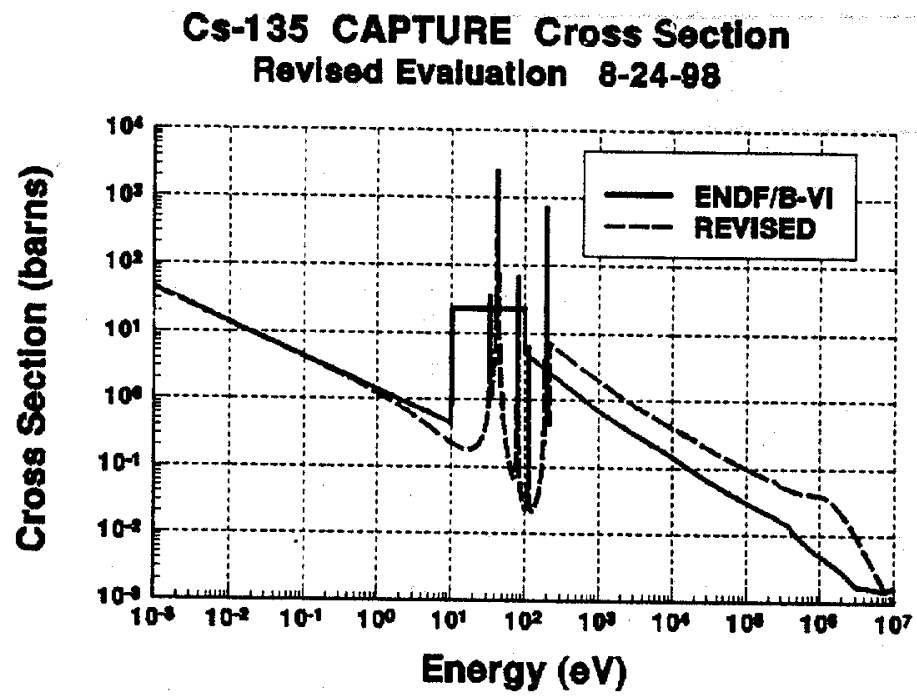

Fig. $22{ }^{135} \mathrm{Cs}$ Capture cross section (revised).

Fig. 23 Fast reactor weight function.

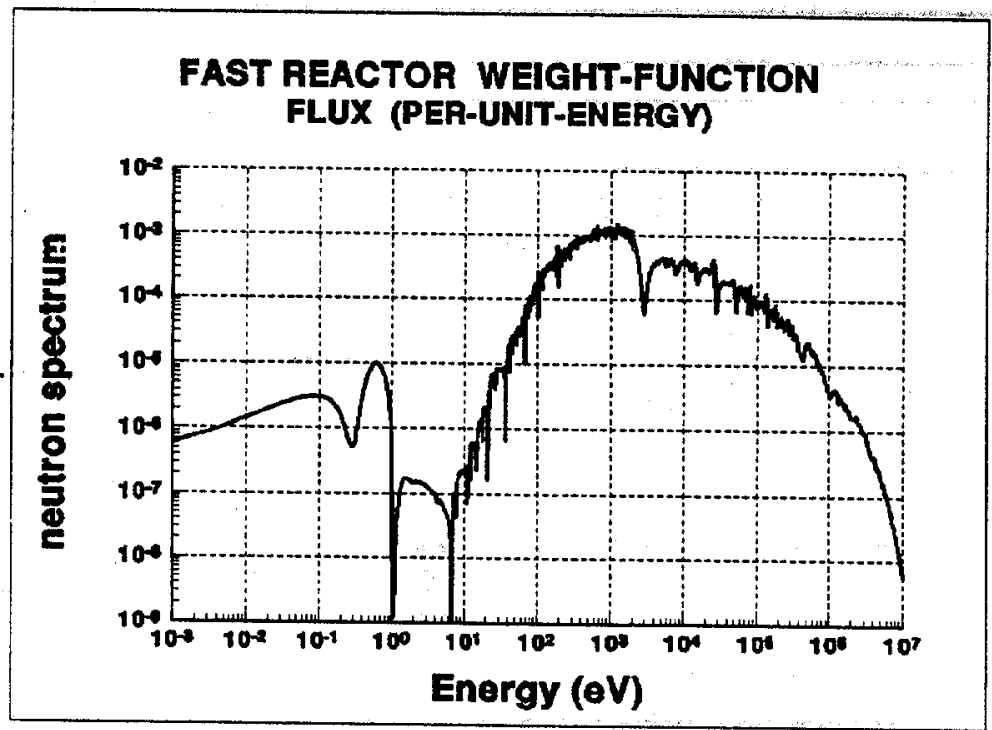




\section{REFERENCES}

1. ENDF/B-IV evaluations were done by various evaluators, thus a single primary reference is not available.

2. R. E. Schenter et al., "Evaluations of Fission Product Capture Cross Sections for ENDF/B-V," Proc. Intl. Conf. on Nuclear Cross Sections for Technology, Knoxville. TN, Oct. 22-26, 1979, NBS Special Publication 594, 662-666 (Sept. 1980).

3. R. Q. Wright, "Fission Product Evaluations for ENDF/B-VI," Trans. Am. Nucl. Soc. 61, 398-399, (June 1990).

4. R. Q. Wright, "Revised Evaluations for ENDF/B-VI Revision 2," Trans. Am. Nucl. Soc. 68, 468-470, (June 1993).

5. S. F. Mughabghab, Neutron Cross Sections, Vol 1, Academic Press, New York (1984).

6. B. D. Murphy, Prediction of the Isotopic Composition of Discharged UO2 Fuel: Analysis of the DUI Sample from the Dodewaard Reactor, ORNL/TM-13687, Oak Ridge National Laboratory (October 1998).

7. B. L. Broadhead et al., Investigation of Nuclide Importance to Functional Requirements Related to Transport and Long-Term Storage of LWR Spent Fuel, ORNL/TM-12742, Oak Ridge National Laboratory (1995).

8. M. D. DeHart, Sensitivity and Parametric Evaluations of Significant Aspects of Burnup Credit for PWR Spent Fuel Packages, ORNL/TM-12973, Oak Ridge National Laboratory (1996).

9. A. Jonsson, "Initial Physics Evaluation of Erbium as a Burnable Absorber in a PWR," Trans. Am. Nucl. Soc. 61, 340-341 (June 1990).

10. P. S. W. Chan et al., "CANDU-A Versatile Reactor for Plutonium Disposition or Actinide Burning," A tomic Energy of Canada Limited (AECL), paper given at GLOBAL '97, International Conference on Future Nuclear Systems, Yokohama, Japan, 1997 October 5-10.

11. Z. Y. Bao and F. Kappeler, "Neutron Capture Cross Sections for s-Process Studies," Atomic Data and Nuclear Data Tables 36, 411-451 (1987).

12. P. Koehler et al., Phys Rev C, 54, 1463 (1996).

13. N. M. Larson, Updated Users' Guide for Sammy: Multilevel R-matrix Fits to Neutron Data Using Bayes' Equations, ORNL/TM-9179R1 (1985), /R2 (1989), /R3 Oak Ridge National Laboratory (1996).

14. V. A. Bondarenko et al., Nuclear Physics A551, 54-72 (1993). 
15. K. Wisshak et al., "Neutron Capture in ${ }^{148,150} \mathrm{Sm}$ : A Sensitive Probe of the s-process Neutron Density," Phys Rev C, 48, 1401 (1993).

16. T. Sekine et al., Applied Radiation and Isotopes, 38, 513 (1987).

17. H. Beer et al., Phys Rev C, 30, 464 (1984).

18. V. N. Kononov et al., "Fast Neutron Radiative Capture Cross-sections and D-wave Strength Functions," Fourth International Symposium on Neutron-capture Gamma-ray Spectroscopy and Related Topics, 7-11 September 1981, Grenoble (1981).

19. R. L. Macklin et al., LA-7479 (1978).

20. S. Jaag and F. Kappeler, "Stellar (n,gamma) cross section of the unstable isotope ${ }^{155}$ Eu," Phys Rev C, $51,3465(1995)$.

21. "Status of Pseudo-Fission-Product Cross-Section for Fast Reactors," International Evaluation CoOperation, Volume 17, NEA/WPEC-17, OECD (1998). 
ORNL/TM-13723

\section{INTERNAL DISTRIBUTION}

1. B. L. Broadhead

2. M. D. DeHart

3. M. E. Dunn

4. K. R. Elam

5. C. Y. Fu

6. I. C. Gauld

7. N. M. Greene

8. C. M. Hopper

9. D. T. Ingersoll

10. M. A. Kuliasha

11. N. M. Larson

12. L. C. Leal

13. R. H. Morris

14. B. D. Murphy
15. C. V. Parks

16. L. M. Petrie

17. R. T. Primm, III

18. J. P. Renier

19. B. Rooney

20. R. W. Roussin

21. T. Valentine

22. R. M. Westfall

23. J. E. White

24-28. R. Q. Wright

29. ORNL Central Research Library

30. Laboratory Records

31-32. Laboratory Records (OSTI)

\section{EXTERNAL DISTRIBUTION}

33. Lance J. Agee, System Sfty \& Licensing Analysis, EPRI, P.O. Box 10412, Palo Alto, CA 94304

34. R. Anderson, Los Alamos National Laboratory, MS J562 NIS-6, Los Alamos, NM 87545

35. P. Angelo, Lockheed Martin Energy Systems, P.O. Box 2009, Bldg. 9110, Oak Ridge, TN 37831-8238

36. Alan M. Baxter, Reactor Engg., General Atomics, P.O. Box 85608, San Diego, CA 92186-5608

37. Sam E. Berk, J-222, U.S. Department of Energy, 19901 Germantown Road, Germantown, MD 20874-1290

38. Jean Blachot, SPSMS/LiH, CEN/G, 17 R des Martyrs, F-38054 Grenoble Cedex 9, France

39. Robert C. Block, Dir. Gaerttner LINAC Lab. Dept. of Environmental \& Energy Engg., 110 8th St., RPI, Troy, NY 12180-3590

40. R. Blomquist, Argonne National Laboratory, MS RA-208, 9700 S. Cass Ave., Argonne, IL $60439-4842$

41. J. Blair Briggs, Idaho National Engineering Lab., P.O. Box 1625, Idaho Falls, ID 83415-3860

42. D. E. Cabrilla, U. S. Dept. of Energy, NE-40, Germantown, MD 20874-1290

43. Dr. Allan D. Carlson, Natl. Inst. of Standards \& Technol., Gaithersburg, MD 20899-8463

44. D. Carlson, U.S. Nuclear Regulatory Commission, MS O-6G22, NMSS Spent Fuel Project Office, Washington, DC 20555

45. Dr. Mark B. Chadwick, Los Alamos National Laboratory, Group T-22, P.O. Box 1663, Los Alamos, NM 87545-1663

46. Dr. Yungan A. Chao, Westinghouse Electric Corp., Commercial Nuclear Fuel Division, P.O. Box 355, Pittsburgh, PA 15230-0355

47. Dr. Edward T. Cheng, TSI Research, Suite 203, 225 Stevens Ave., Solana Beach, CA 92075-2040

48. Dr. Dermott E. Cullen, Lawrence Livermore National Laboratory, MS L-59, P.O. Box 808, 
Livermore, CA 94551-0808

49. Dr. Ulrich Decher, ABB Combustion Eng., GC-28, P.O. Box 500, Windsor, CT 06095

50. R. Dintaman, U.S. Dept. of Energy, DP-17, Germantown, MD 20874-1290

51. Dr. Charles L. Dunford, National Nuclear Data Center, Bldg, 197D, P.O. Box 5000, Upton, NY 11973-5000

52. Talmadge R. England, Los Alamos National Laboratory, T2, MS B-243, P.O. Box 1663, Los Alamos, NM 87545-1663

53. M. Feltus, U.S. Department of Energy, Forrestal Building, Room 5A-143, 1000 Independence Ave. SW, Washington, DC 20585

54. J. Felty, U.S. Dept of Energy, DP-45, Germantown, MD 20874-1290

55. I. Fergus, U.S. Department of Energy, EH-22, 20300 Century Blvd., Germantown, MD 20874

56. P. Finck, Argonne National Laboratory, 9700 S. Cass Avenue, Argonne, IL 60439

57. Matthew Forsbacka, Defense Nuclear Facilities Safety Board, Suite 700, 625 Indiana Ave. NW, Washington, DC 20004

58. A. Forster, Los Alamos National Laboratory, MS F663 X-5, Los Alamos, NM 87545

59. Stephanie C. Frankle, Los Alamos National Laboratory, MS F663, P.O. Box 1663, Los Alamos, NM 87545-1663

60. E. Fujita, Argonne National Laboratory, 9700 S. Cass Avenue, Argonne, IL 60439

61. Tokio Fukahori, Japan Atomic Energy Research Institute, Nuclear Data Center, Tokai-mura, Naka-gun, Ibaraki 319-11, Japan

62. A. Garcia, U.S. Department of Energy, Idaho Field Office, MS 1154, 850 Energy Drive, Idaho Falls, ID 83401-1563

63. Patrick J. Griffin, Sandia National Laboratory, Dept. 9363, P.O. Box 5800, Albuquerque, NM 87185-1146

64. Steven M. Grimes, Dept. of Phys. \& Astronomy, Ohio Univ., Athens, OH 45701-2979

65. L. Michael Gundy, Westinghouse Savannah River Co., P.O. Box 616, Aiken, SC 29802

66. Akira Hasagawa, Japan Atomic Energy Research Institute, Nuclear Data Center, Tokai-mura, Naka-gun, Ibaraki 319-11, Japan

67. Norman E. Holden, Reactor Div., Brookhaven Natl. Lab., P.O. Box 5000, Upton, NY 119735000

68. S. Huang, Lawrence Livermore National Laboratory, MS L-128, P.O. Box 808, Livermore, CA 94551-0808

69. M. Hutmaker, U.S. Dept. of Energy, NE-40, Germantown, MD 20874-1290

70. Richard N. Hwang, Argonne National Laboratory, 9700 S. Cass Ave., Argonne, IL 60439-4842

71. R. Jacqmin, Atomic Energy Commission, CEA Cadarache, SPRC/LEPH BAT. 230, St-Paul-Lez-Durance 13108, France

72. H. Johnson, U.S. Department of Energy, Forrestal 1F-082, Washington, DC 20585

73. Albert Kahler, Bettis Atomic Power Lab., ZAP34F, P.O. Box 79, West Mifflin, PA 151220079

74. Jun-ichi Katakura, Nucl. Data Ctr., Japan Atomic Energy Research Inst., 2-4 Shirakatashirane, Tokai-mura, Naka-gun, Ibaraki-ken 319-1195, Japan

75. W. Lake, RW-431, 7F-043/FORS, U.S. Department of Energy, Washington, DC 20585

76. Robert C. Little, Los Alamos National Laboratory, MS F663, P.O. Box 1663, Los Alamos, NM 87545-1663

77. Cecil Lubitz, Knolls Atomic Power Lab., Bldg. F3-7, MS 9, P.O. Box 1072, Schenectady, NY 12301-1072

78. Liu Tingjin, Chinese Nuclear Data Center, China Inst. of Atomic Energy, P.O. Box 275-41, Beijing 102413, PRC 
79. Liu Yunzuo, Dept. of Phys., Jilin Univ., Changchun 130023, PRC

80. M. Aslam Lone, Chalk River Nuclear Labs., AECL, Chalk River, Ontario, K0J 1 J0 Canada

81. Jose M. Los Arcos, Metrologia de Radiaciones, Avda. Complutense 22, Centro de Investigacion, Energetica Medioambientales y Tecnologicas, 28040 Madrid, Spain

82. Cecil Lubitz, Knolls Atomic Power Lab., Bldg. F3-7, MS 9, P.O. Box 1072, Schenectady, NY 12301-1072

83-87. Robert E. MacFarlane, Los Alamos Natl. Lab., Group T-2, MS B243, P. O. Box 1663, Los Alamos, NM 87545-1663

88. V. N. Manokhin, Fed. Res. Ctr., Inst. of Physics \& Power Engineering, Bondarenko Sq. 1, 249020 Obninsk, Kaluga Reg., Russian Federation

89. Alfredo Marchetti, Dept. of Environmental Protection, L-396, Lawrence Livermore Natl. Lab., P.O. Box 808, Livermore, CA 94550

90. M. T. McEllistrem, Dept. of Phys. \& Astronomy, Univ. of Kentucky, Lexington, KY 405060055

91. J. McKamy, EH-34, U.S. Department of Energy, MS CXXI/3, 19901 Germantown Road, Germantown, MD 20874-1290

92. Richard D. McKnight, Argonne National Laboratory, MS RA208, 9700 S. Cass Ave., Argonne, IL 60439-4842

93. Victoria McLane, National Nuclear Data Center, Brookhaven National Laboratory, Bldg, 197D, Upton, NY 11973-5000

94. T. McLaughlin, Los Alamos National Laboratory, MS F691 ESH-6, Los Alamos, NM 87545

95. Richard A. Meyer, Off. of Sci., Div. Of Nucl. Phys., ER-23 GTN, U.S. Dept. of Energy, 19901 Germantown Rd., Germantown, MD 20876-1290

96. J. Morman, Argonne National Laboratory, Bldg, 208, 9700 S. Cass Ave., Argonne, IL $60439-4842$

97. Russell D. Mostefler, Los Alamos National Laboratory, Group NIS-6, MS F663, P.O. Box 1663, Los Alamos, NM 87545-1663

98. Douglas W. Muir, IAEA, Nuclear Data Section, P.O. Box 200, A-1400 Vienna, Austria

99. C. Nilson, NRC, TWFN, 11545 Rockville Pike, Rockville, MD 20785

100. Claes Nordborg, Nucl. Sci. Div., OECD NEA Data Bank, Le Seine Saint-Germain, 12 blvd. des Iles, F-92130 Issy-les-Moulineaux, France

101. Sol Pearlstein, National Nuclear Data Center, Brookhaven Natl. Lab., Bldg. 197D, P.O. Box 5000, Upton, NY 11973

102. V. Perin, U.S. Nuclear Regulatory Commission, T-10 K8, 11545 Rockville Pike, Rockville, MD 20852

103. Vladimir G. Pronyaev, Scientific Secretary, IAEA, Nuclear Data Section, P.O. Box 100, A-1400 Vienna, Austria

104. T. A. Reilly, Westinghouse Safety Management Solutions, 1993 South Centennial Dr., Aiken, SC 29803

105. David A. Resler, Inst. of Nucl. \& Particle Phys., Ohio University, Athens, $\mathrm{OH} 45701$

106. J. Roarty, Defense Nuclear Facilities Safety Board, Suite 700, 625 Indiana Ave. NW, Washington, DC 20004

107. John M. Ryskamp, Idaho National Engineering \& Environmental Lab., P.O. Box 1625, Idaho Falls, ID 83415-3885

108. Donald L. Smith, Nucl. Data Prog., Technol. Dev. Div., Bldg. 360 MS L106, Argonne National Laboratory, 9700 S. Cass Ave., Argonne, IL 60439

109. I. Thomas, ER-13, U.S. Department of Energy, Bldg, GTN MS F-406, 19901 Germantown Road, Germantown, MD 20874-1290

110. Mercury Vlasov, Inst. of Nucl. Research, Prospect Nauky, 47, Kyiv 22, 252650 Ukraine 
111. James P. Weinman, Bldg. E6, Room 208, Knolls Atomic Power Laboratory, P.O. Box 1072, Schenectady, NY 12301-1072

112. Charles A. Wemple, Idaho Natl. Eng. \& Env. Lab., P.O. Box 1625, Idaho Falls, ID 83415-3885

113. Mark L. Williams, LSU Nuclear Science Center, Louisiana State University, Baton Rouge, LA 70803

114. R. E. Wilson, Safe Sites of Colorado, P.O. Box 464, Golden, CO 80402-0464 
